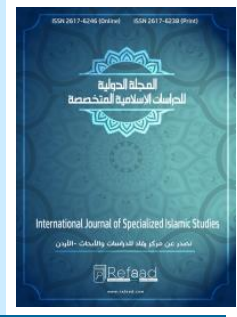

\title{
المعاهدات الدولية وصلح الحديبية (دراسة تحليلية مقارنة)
}

\author{
د. وسام محمود الطيطي \\ باحث- المملكة الأردنية الهاشمية \\ wesam.titi@yahoo.com
}

DOI: https://doi.org/DOI:10.31559/sis2019.3.2.2

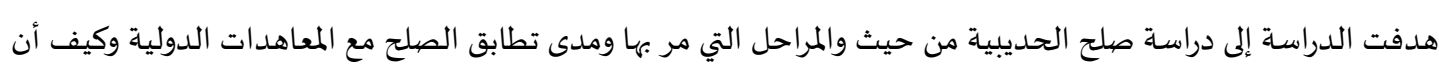

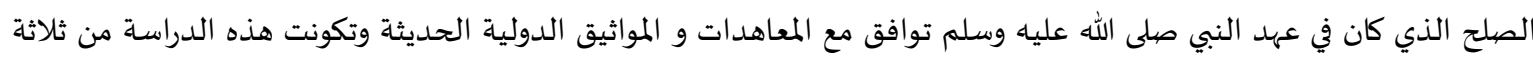

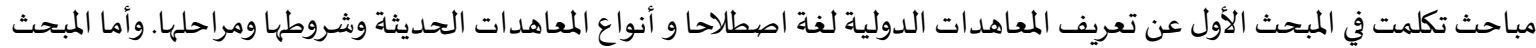

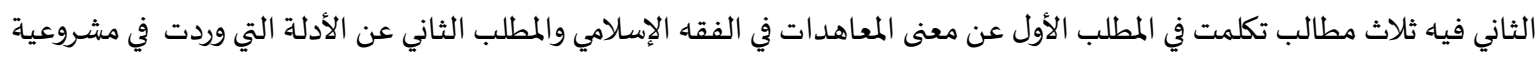

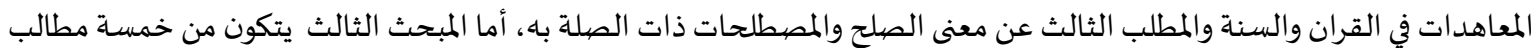

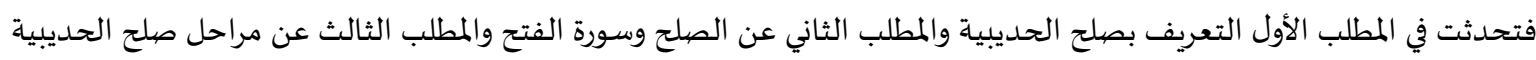

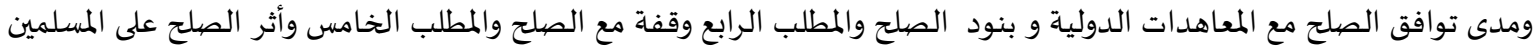
وأخيرا وضعت الخاتمة وفهيها أهم النتائج والتوصيات المعات الدولية بنود المعات

الكلمات المفتاحية: المعاهدات؛ الدولية؛ صلح؛ الحديبة. (9) (1)

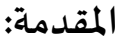

الحمد الله رب العالمين، الذي خلق الإنسان في أحسن تقويم، وعلمه البيان، وكرمه فحمله في البر والبحر ورزقه، وجعله خليفة في الأرض وفضله على كثير ممن خلق، والصهاة والسلام على رسول الله، خير الأنام المبعوث رحمة للعالمين، خلقهاه الله تعالى وكمله،

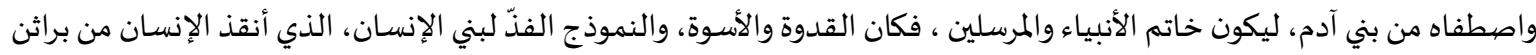

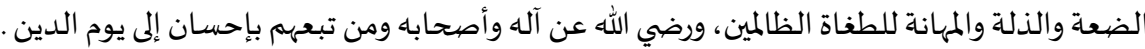

فإن قضية المعاهدات الدولية من القضايا التي تشغل العالم اليوم بمختلف دوله وشعوبه، ودياناته وجنسياته، وفئاته وطبقاته، بين محق فيها ومبطل، لما لهذا المصطلح من تأثير كبير في توجياء السياسـة الدولية ؛ فأصبح هذا المصطلح أحد المعايير المهمة في تحديد العلاقات والمعاملات الدولية، إذ أخذت هذه العلاقات تتبلور وتتشكل طبقاً لحالة حقوق الحهات الإنسان في سياسات الدول، وانطلاقاً

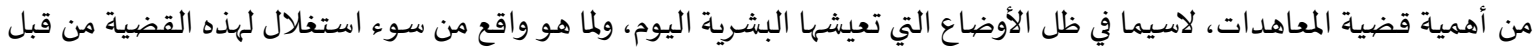
دول الغرب، فقد ضيعت حقوق وواجبات وأشعلت حروب وأزهقت نفوس، بل أزبلت دول واستبدلت أنظمة، ونتيجة لتسلط العالم الغربي واستبداده، وفرض هيمنته الفكرية والإعلامية على كثير من دول العالم، ولاسيما العالم العربي والإسلامي، وفي ظل هذه الهجمية

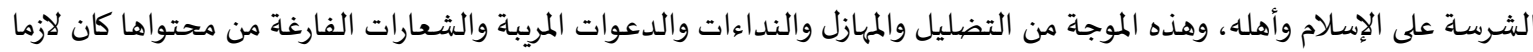
على أهل الاستلام للتوجه ودراسة تلك المواثيق والمعاهدات واستخلالها لما هو في صالح الإسلام والمسلمين ولا سيما أن أهل الإسلام يعيشون في ضعف وهوان فلا بد من استغلالها والعمل عليها بما يتوافق مع شريعتنا السمحة وكيف ولا وان الإسلام صالح لكل زمان 
السبب في اختيار الموضوع .

أن مصطلح "المعاهدات الدولية "مصطلح حديث وهناك مجال في البحث في الموضوع وتأصيله تأصيلا شرعيا والسبب يعود في ذلك إلى نشوء الدول والمواثيق الدولية التي من شانها أن تحافظ على سيادة المعاد كل دونات دولة وعدم الاعتداء على أي منها ومدى تلك القوانين

ومواءمتها مع الشريعة.

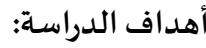

يمكن إبراز أهمية دراسـة هذا الموضوع في النقاط الآتية:

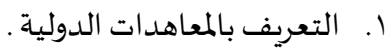

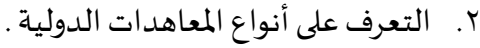

r. التعرف على شروط المعاهدات.

ع. التعرف على مراحل المفاوضات.

0. تسليط الضوء عل صلح الحديبية ومدى موافقة الصلح لتلك الأمور .

7. الوقوف على أهم الأمور التي نتجت عن الصلح ومدى اثرها على الدولة الاسلامية. .

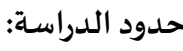

ستتناول هذه الدراسـة -إن شـاء الله- تعريف المعاهدات الدولية والتعريف بصلح الحديبية ومراحله والتعريف ببنود الصلح وأثرها ومدى تطابق الصلح مع المعاهدات الدولية وكيف أن الصلح الذي كان في عهد النبي صلى الاله عليه وسلم توافق مع المواثيق

الدولية الحديثة.

مشكلة الدراسـة:

تتبين مشكلة الدراسة في الإجابة على السؤال الرئيس الآتي؛ وهو: هل مفهوم المعاهدات الدولية له شاهد من السيرة النبوية؟.

وتتفرع من السؤال الرئيس الأسئلة التالية:

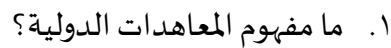

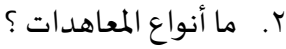

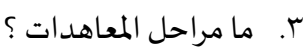

الدراسات السـابقة:

لم أجد فيما قدر الله لي أن بحث أو دراسة أو بحث متخصص تناول الموضوع من باب مقارنة صلح الحديبية مع المعاهدات

الدولية ولا شك أنه من المراجع الهامة لهذه الدراسـة، كتب السيرة والتاريخ العامة؛ ودراسات متفرقة لبعض المعاصرين مثل :-

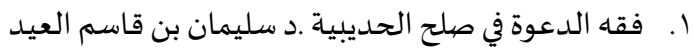
r. صلح الحديبية وفقه المآلات د. خالد راتب

$$
\text { المنهج المتبع في هذه الدراسة: }
$$

أولاً: المنهج الوصفي المقارن، المعتمد على تتبع المباحث التي ستتناولها الدراسة.

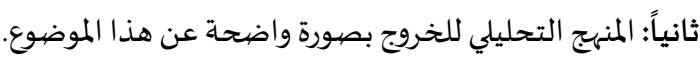

ثالثا: المنهج الاستقرائي

خط البحث:

تتكون الدراسة من ثلاثة مباحث.

المبحث الأول : المعاهدات وشروطها وأنواعها وفياه خمس مطالب وفيه ستة مطالب.

المطلب الأول :تعريف المعاهدات لغة :المعاتة

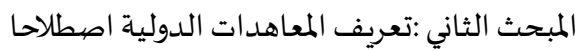




$$
\begin{aligned}
& \text { المطلب الثالث: خصيائص المعاهدات } \\
& \text { المطلب الرابع:- أنواع المعاهدات الحديثة } \\
& \text { وفياء ثلاثة فروع } \\
& \text { الفرع الأول: تصنيف المعاهدات من حيث عدد الدول الأطراف. } \\
& \text { الفرع الثاني: تصنيف المعاهدات من حيث الطبيعة. } \\
& \text { الفرع الثالث: تصنيف المعاهدات من حيث إجراءات الإبرام من حيث الشكل من حئل } \\
& \text { المطلب الخامس: شروط المعاهدات } \\
& \text { المطلب السـادس: مراحل إجراءات إبرام المعاهدة. }
\end{aligned}
$$

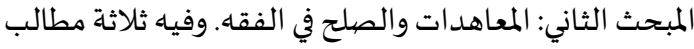

$$
\begin{aligned}
& \text { المطلب الأول: معنى المعاهدات لغة واصطالياحا. } \\
& \text { المطلب الثاني: الأدلة على مشروعية المعاهدات. }
\end{aligned}
$$

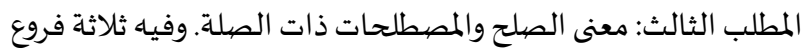

$$
\begin{aligned}
& \text { الفرع الأول: معنى الصلح لغة. } \\
& \text { الفرع الثاني معنى الصبلح اصطلاحا. } \\
& \text { الفرع الثالث المصطلحات ذات الصلة بالصبلح. }
\end{aligned}
$$

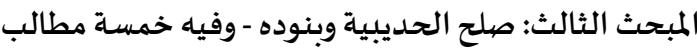

$$
\begin{aligned}
& \text { المطلب الأول: التعريف بصلح الحديبية. } \\
& \text { المطلب الثاني: سورة الفتح وصلح الحديبية :-وفيه ثلاثة فروع. } \\
& \text { الفرع الأول : رؤيا النبي لمئي }
\end{aligned}
$$

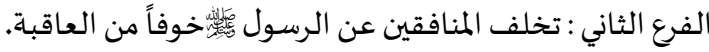

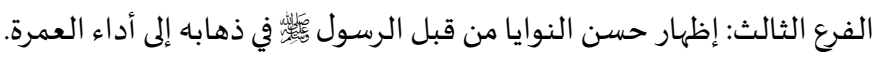

$$
\begin{aligned}
& \text { المطلب الثالث: مراحل صلح الحديبية, ومقارنته بالمعاهدات الدولية. } \\
& \text { المطلب الر ابع : وقفة مع اتفاقية الصلح. وفيه ثلاثة فروع:- } \\
& \text { الفرع الأول: إيجابيات معاهدات الصلح. } \\
& \text { الفرع الثاني: سلبيات معاهدات الصاتح. } \\
& \text { الفرع الثالث: دور المرأة المسلمة في اتخاذ القرار والمشاركة في الحياة السياسة } \\
& \text { المطلب الخامس: الصلح و أثرة على المسلمين. }
\end{aligned}
$$

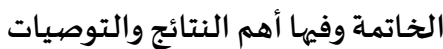

$$
\text { المبحث الأول : المعاهدات وشروطها و أنواعها وفيه خمس مطالب }
$$

$$
\text { المطلب الأول : تعريف المعاهدات لغة: }
$$

المعاهدات مأخوذة من ( عهد )، فلان إلى فلان عهدا ألقى إليه العهد وأوصاه بحفظه ويقال عهد إليه بالأمر وفيه أوصاه باه بهاه

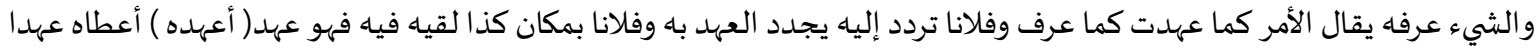

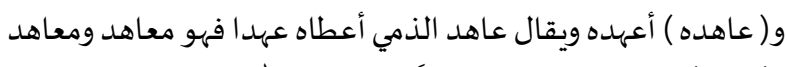

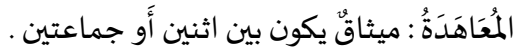


المطلب الثاني: تعريف المعاهدات الدولية اصطلاحاً:

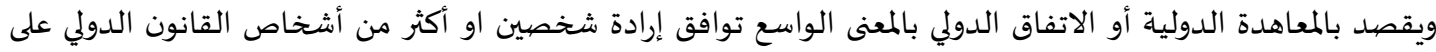

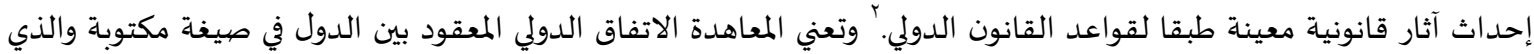

ينظمه القانون الدولي سواء تضمنته وثيقة واحدة أو وثيقتان او أكثر.

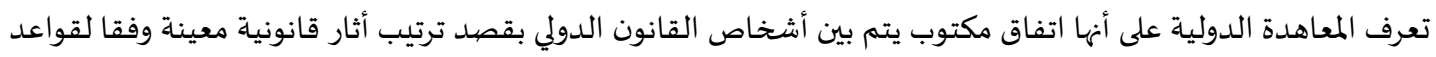

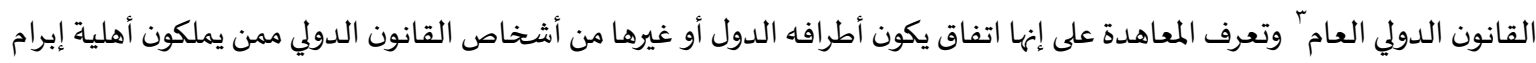

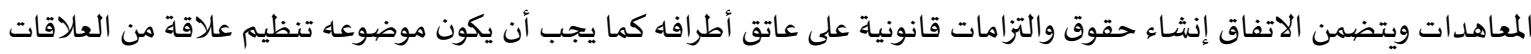
التي يحكمها القانون الدولي. وعرفت المادة الثانية من معاهدة فينا للمعاهدات التي تعقد بين الدول بأنها :- أتفاق بين الدول ويكون الاتفاق خطيا بويترتب على التان

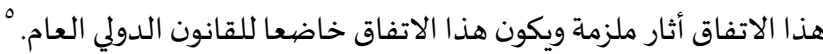

المطلب الثالث: خصيائص المعاهدة: ا. أن الاتفاقية أو المعاهدة هي اتفاق يعبر عن التقاء إرادات موقعيها على أمرٍ ما، فهي ذات صففة تعاقدية لغرض إنشاء علاقة

$$
\text { قانونية بين الأطراف المتعاقدة. }
$$

r. الاتفاقية أو المعاهدة هي اتفاق مكتوب ولذا لاتعد الاتفاقات الشفوية ولاسيما ما يعرف باتفاقيات الجنتلمان أو ما يسميه

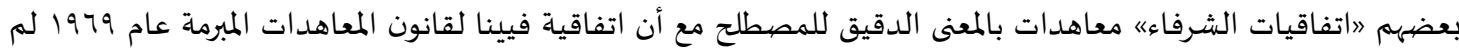
تنكر ما قد يكون لهذه الاتفاقات الشفوية من قيمة قانونية. r. والاتفاقية الدولية بين شخصين أو دوليين أو أكثر، وهذا يعني أهها قد تكون بين دول، وقد تكون بين دولة ومنظمة دولية، وقد تكون بين منظمات دولية. ع. والمعاهدة هي الاتفاق الذي من شأنه أن ينشئ حقوقاً والتزامات متبادلة بين الأطراف المرتبطة، يحكمها القانون الدولي العام. ح المطلب الر ابع: أنواع المعاهدات:

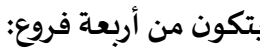
الفرع الأول : تصنيف من المعاهد فروع: تضف المعاهدات من هذه الناحية إلى معاهدات ثنائية ومعاهدات جماعية أو متعددة الأطراف وتعقد بين عدة دول. أولاً: معاهدات ثنائية: إذا كانت المعاهدة ثنائية كانت المشكلة الناجمة عن التحفظات قليلة أن الطرف الأخر إما أن يبرم الاتفاقية مع التحفظات

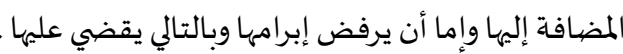

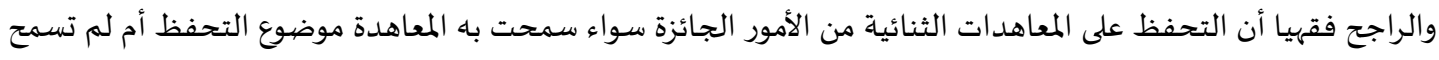
وانه يعتبر في جميع الأحوال بمثابة إيجاب جديد او اقتراح بالتعديل ومن ثمة يتوقف مصيره بل ومصير المعاهدة بكاملها على موقف ألفاء

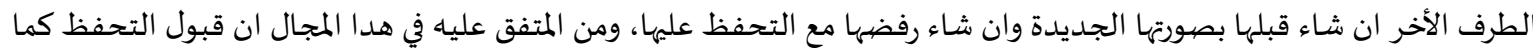
يتم صراحة قد يتم أيضا بطريقة ضمنية وان السكوت عن رفض التحفظ صراحة يعتبر بعد مضي اثنا عشر شهرا من تاريخ استشارة

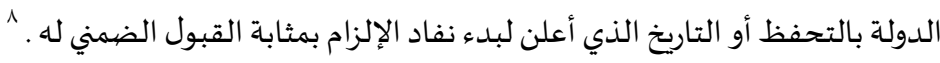

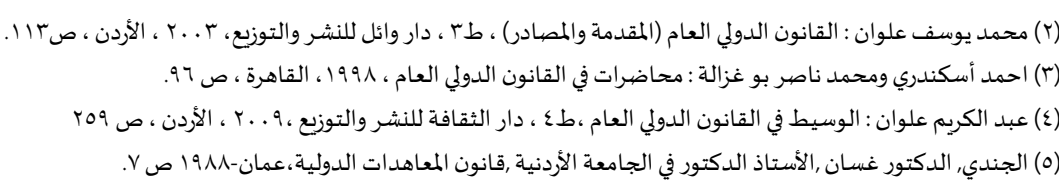

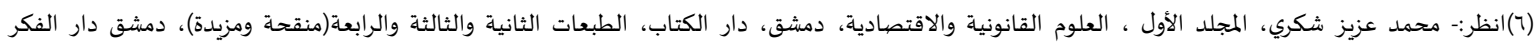
(09)(1919.191..19VV.19Vr

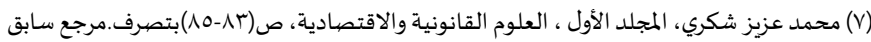

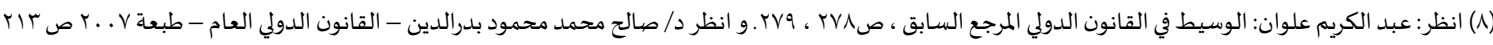


ثانياً : معاهدات متعددة الأطراف (جماعية):

المعاهدات الجماعية تشترك في أن عدد أطرافها يزيد عن دولتين ،وهي قد تكون من حيث المدى الجغرافي إقليمية وقد تكون ذات

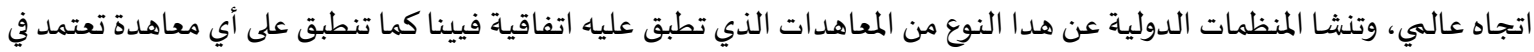
نطاق منظمة دولية وعدد المعاهدات الجماعية كبير للغاية، لكنه أقل من المعاهدات الثنائية وهي من حيث الموضهوع قد تكون ذات

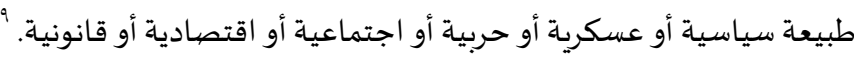

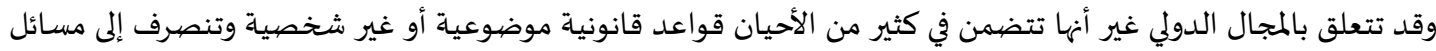

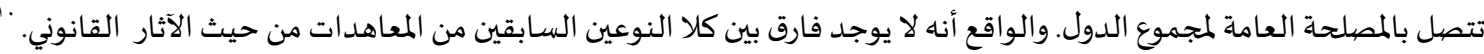
الفرع الثاني: تصنيف المعاهدات من حيث الطبيعة: ابرز بعض الفقهاء مند زمن طويل الوظائف التي تؤديها المعاهدات الدولية وعدم خضيوعها لنظام قانوني موحد و يرى هؤلاء أن

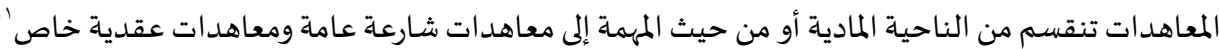

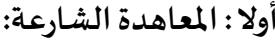

هي الاتفاقيات ذات الطبيعة الشارعة فهي التي يهدف أطرافها من وراء إبرامها سن قواعد دولية جديدة تنظم العلاقات بين

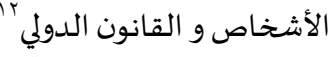

$$
\begin{aligned}
& \text { ثانياً :المعاهدات العقدية } 1 \text { العاهن }
\end{aligned}
$$

فالاتفاقيات التي تعد من العقود هي تلك التي تبرم بين الأشخاص القانون الدولي في أمر خاص بهم ، أي بين دولتين أو عدد محدد

من الدول أو بين شخص دولي فرد أو هيئة خاصة. الفرع الثالث : تصنيف المعاهدات من حيث إجراءات الإبرام من حيث دوليث الشكل فئه تنقسم المعاهدات من حيث أسلوب التعبير عن الرضا النهائي والالتزام بها إلى معاهدات بالمعنى الضيق أو الشكلي ومعاهدات

تنفيذية

أولاً: المعاهدات بالمعنى الضيق معاهدات مطولة أو ارتسامية:

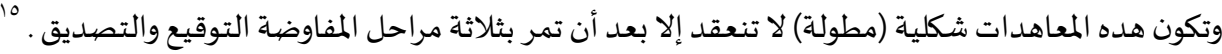

ثانياً: معاهدات مبسطة أو تنفيذية:

عادة ما يكون الاتفاق التنفيذي في أكثر من أداة قانونية ،فهو يتم التبادل الرسائل أو المذكرات أو الخطاباتهات أو التصريحات أو بالتوقيع على محضر مباحثات ويشترط في إبرامها المرور بمرحلتين فقط المفاوضية والتوقيع ولا يلزم لنفادها التصديق عليقيها من السلطة

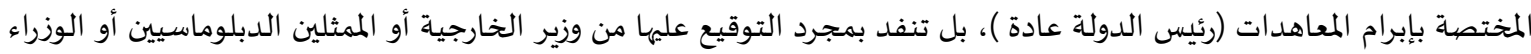

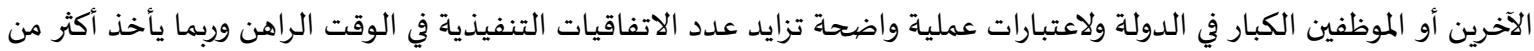

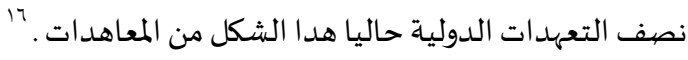

المطلب الخامس: شروط المعاهدات:

أولاً: أهلية التعاقد:

يعد إبرام المعاهدة من مظاهر سيادة الدولة وبالتالي الدولة الكاملة السيادة هي من تملك إبرام المعاهدات أياً كان نوعها، أما الدول

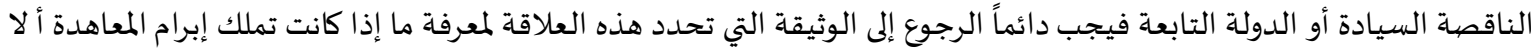

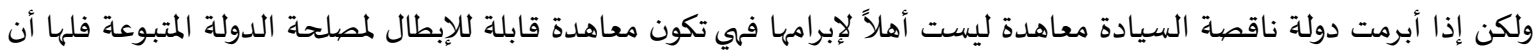

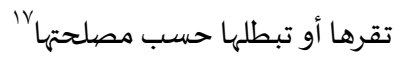

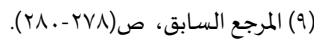

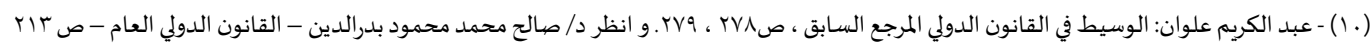

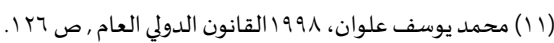

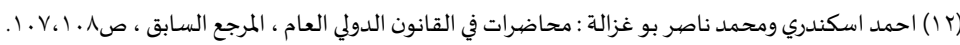

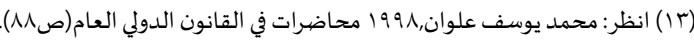

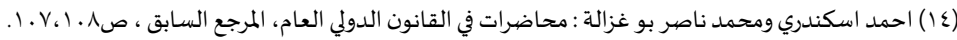

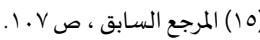

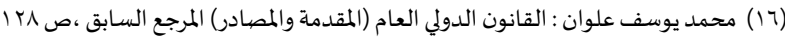

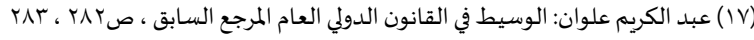


لا تكفي أهلية التعاقد لصحة المعاهدة، بل يلزم أيضاً أن تكون الإدارة المعبر عنها في المعاهدة منسوبة إلى الدولة وأن تكون

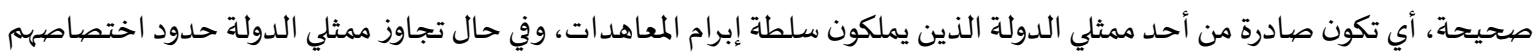
أو التفويض الممنوح لهم فلا يمكن الاحتجاج بذلك تجاه الدول الأخرى إلا إذا كانت مخالفتهم صريحة وتتصل بقاعدة قانونية جوهرية

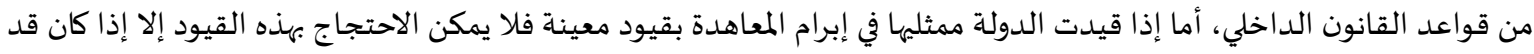
سبق إعلانها للدول الأخرى أطراف المعاهدة.

ويجوز للدولة طلب إبطال المعاهدة وفقاً لاتفاقية فيينا إذا تم إفساد إرادة ممثلها بإغرائه مادياً أو معنوياً، فالمعاهدة لا لا تنعقد

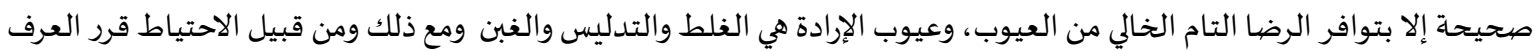

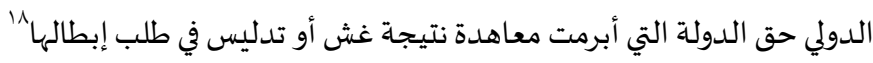

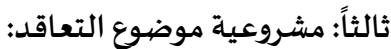

يجب أن يكون موضوع المعاهدة مشروعاً وجائزاً ويكون موضوعها مشروعاً إذا تم الاتفاق على أمر من الأمور التي يبيحها القانون

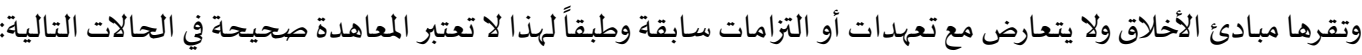

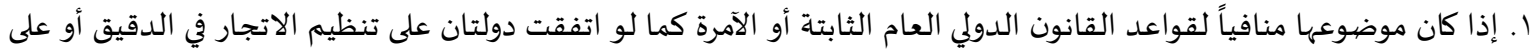

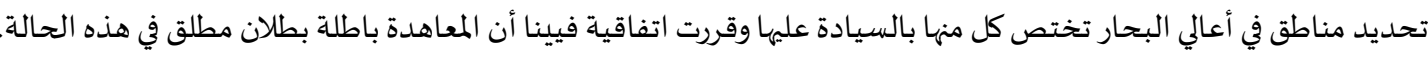
r إذا كان موضوعها منافياً لحسن الأخلاق أو مبادئ الإنسانية العامة، كما لو اتفقت دولتان على اتخاذ تدابير اضطهادية لا مبرر لها

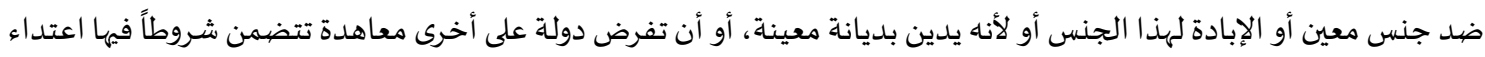

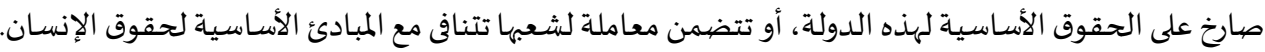

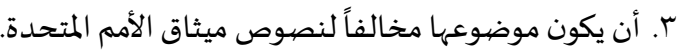

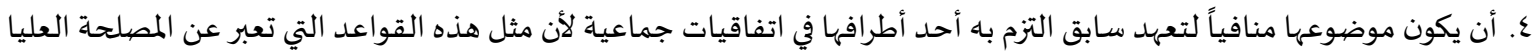

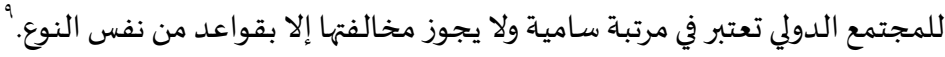

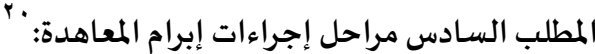
تعتبر المعاهدة تصرف رضائي يتم بشكل معين حتى يمكن وصفها بالمعاهدة الدولية بالمعنى الضيق ، ولذلك فالمعاهدة بهذا المفهوم

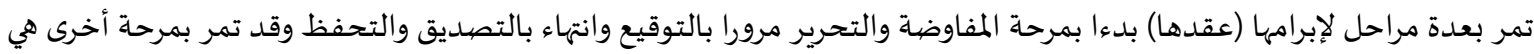

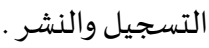
المرحلة الأولى: المفاوضية وتسبقها مرحلة الاتصالات وهي اتصال الدولتين أو العديد من الأطراف للاتفاق مبدئياً على موضوع المعاهد والإجراءات اللازمة

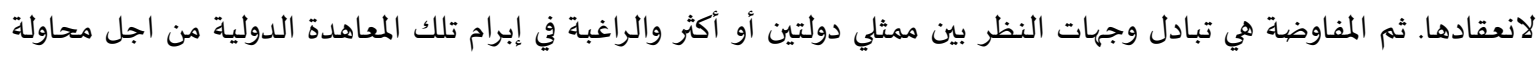

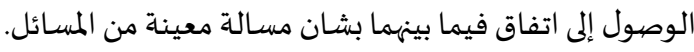

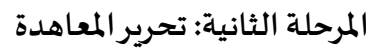

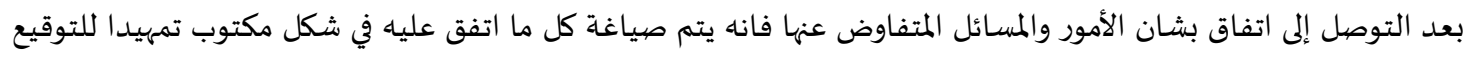
عليا، فتحرير تلك المعاهدة يعد شرطا ضروريا للمعاهدة الدولية واثبات الاتفاق الذي من شانه أن يقطع الخلاف في حال وجوده، ويتكون نص المعاهدة من قسمين أساسيين:

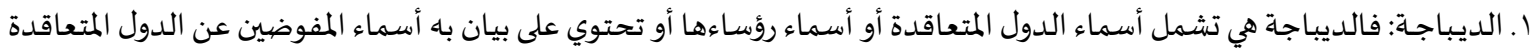
وصفاتهم r. صلب الموضوع : أما صلب المعاهدة (المنطوق) فيتكون من مجموعة من المواد التي تشكل أحكام المعاهدة التي تم الاتفاق عليها وبين أطرافها

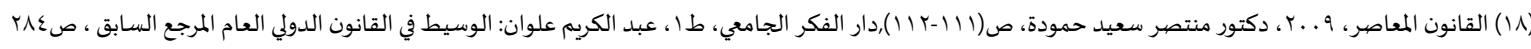


المرحلة الثالثة: التوقيع

بمجرد الانتهاء من مرحلة التفاوض والتحرير، تأتي المرحلة التالية والمتمثلة في التوقيع على نص هده المعاهدة، ودلك من قبل

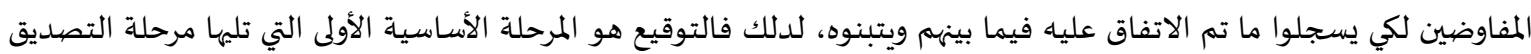

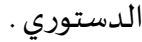

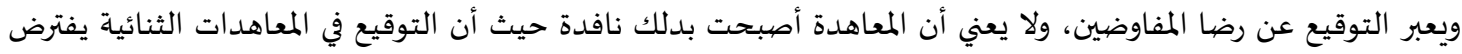

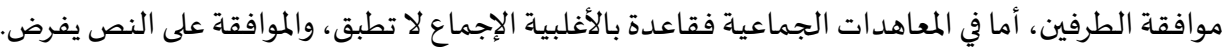

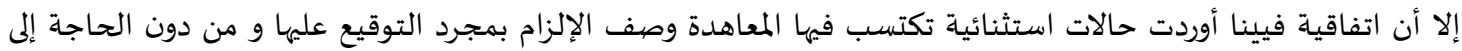

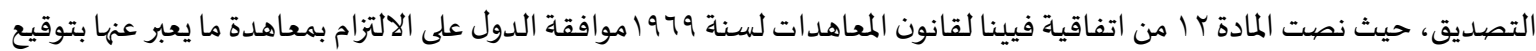
ممثليها من ما يلي:

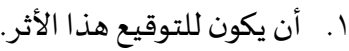
r. ثبت بطريقة أخرى أن الدول المتفاوضة متفقة على أن يكون للتوقيع هدا الأثر.

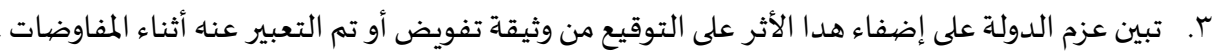

المرحلة الر ابعة: التصبديق لمبيق

يعتبر التصديق على المعاهدة دلك التصرف القانوني الذي يقصديد بهاء الحصول على إقرار السلطات المختصية داخل الدولة للمعاهدة التي تم التوقيع عليها وهده السلطات إما لرئيس الدولة منفردا ، وإما لرئيس الدولة مشتركا مع السلطة التشريعية، وإما

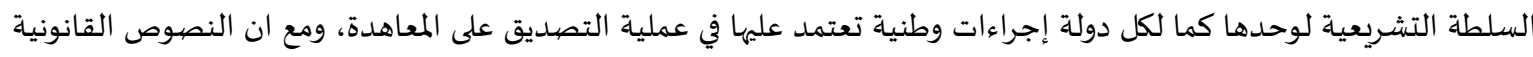

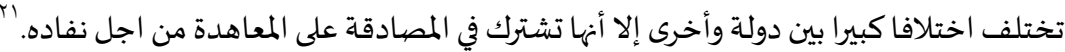
المرحلة الخامسـة: التحفظات

التحفظ إجراء رسمي يصدر عن إحدى الدول أو المنظمات الدولية، وذلك عند التوقيع أو التصديق أو الانضيمام إلى معاهدة

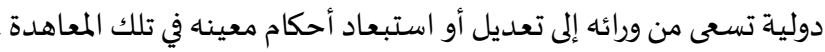

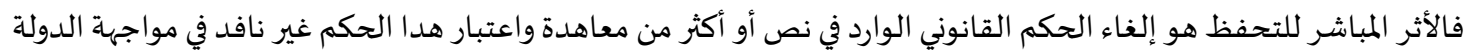
أو المنظمة الدولية التي أبدته أو اعتباره نافدا، ولكن تحت شروط معينة لم ترد في المعاهدة

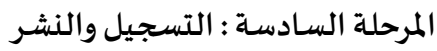

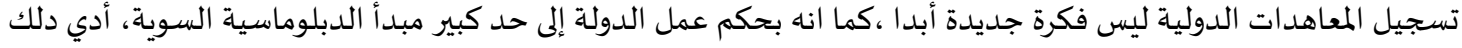

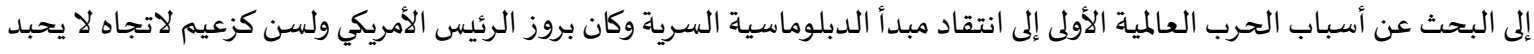
الدبلوماسية المكشوفة ويحبذ التسجيل المعاهدة كوسيلة لنشر أنباء عقدها وتفاصيلها. المبحث الثاني: المعاهدات في الفقه المطلب الأول: معنى المعاهدة لفة واصطلاحا وفيه فرعان:

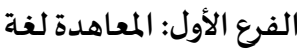
المعاهدات مأخوذة من ( عهد )

فلان إلى فلان عهدا ألقى إليه العهد وأوصياه بحفظه ويقال عهد إليه بالأمر وفيه أوصاه باه والثيء عرفه يقال الأمر كما عهدت كما

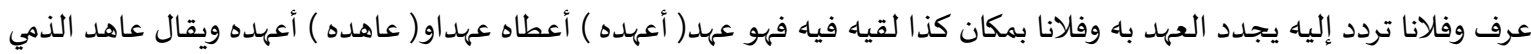
أعطاه عهدا فهو معاهد ومعاهد وتأتي المعهدة بمعنى الوفاء

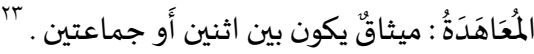

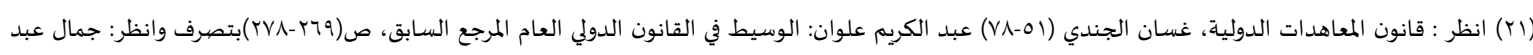

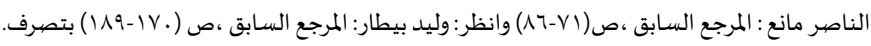

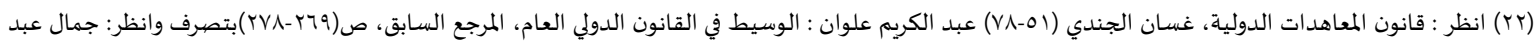

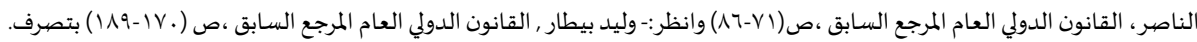

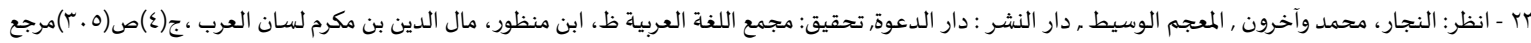


الفرع الثاني: المعاهدة في الاصطلاح

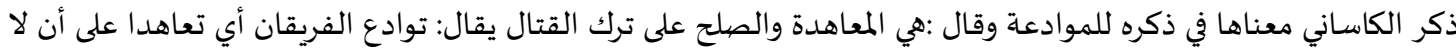

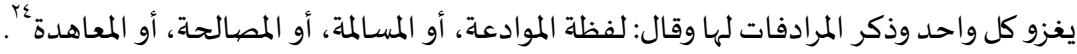

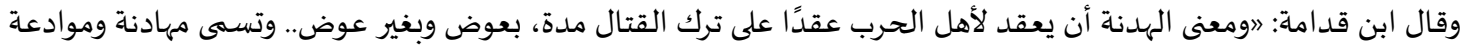

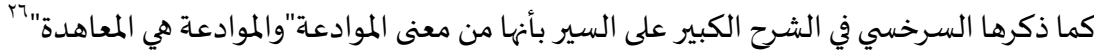

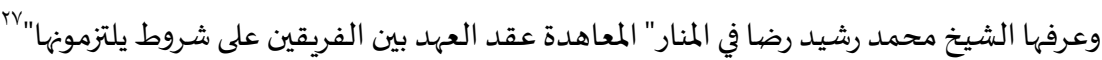

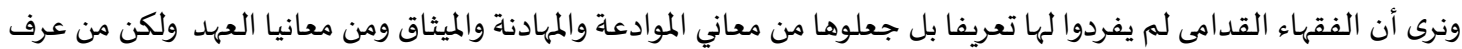

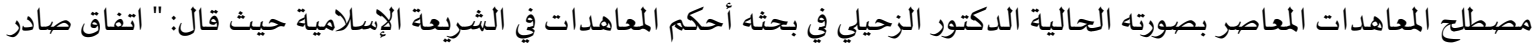

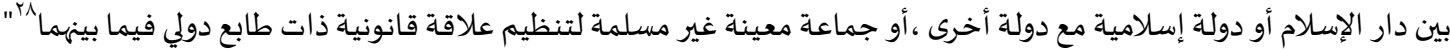

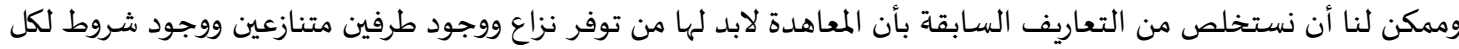
طرف لحل النزاع حتى تتم المعاهدة ولا يوجد أكراه لأي من الطرفين في التوقيع على المعاهدة.

المطلب الثاني: الأدلَّة على مشروعية المعاهدات

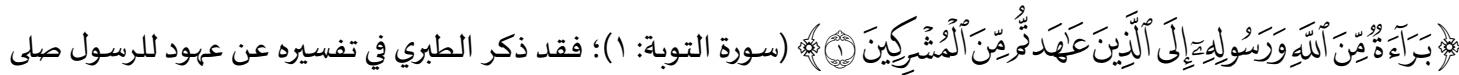

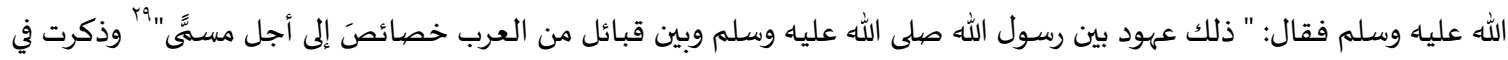

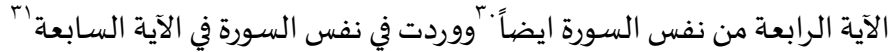

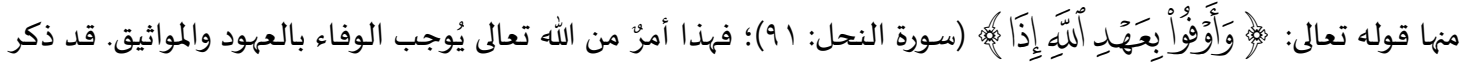
الطبري في تفسير الآية" وأوفوا بميثاق الله إذا واثقتموه، وعقده إذا عاقدتموه، فأوجبتم به على أنفسكم حقا لمن عاقدتموه بها

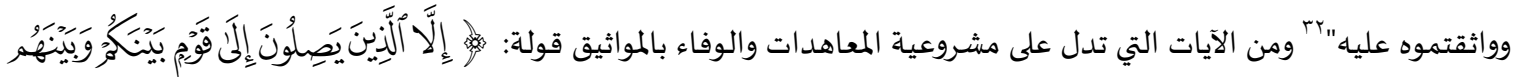

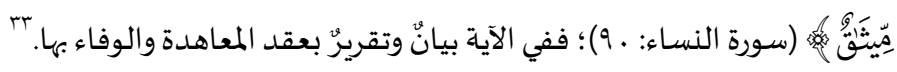

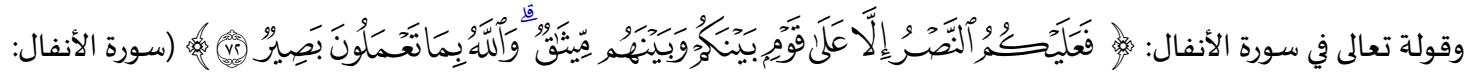

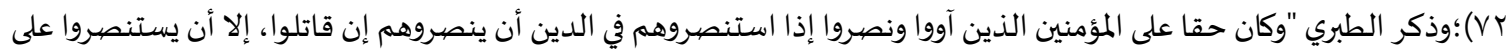

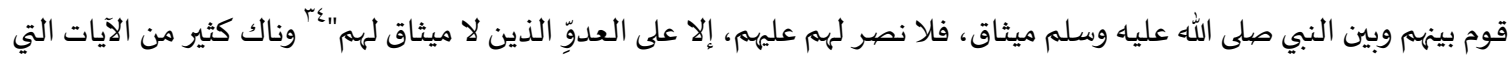

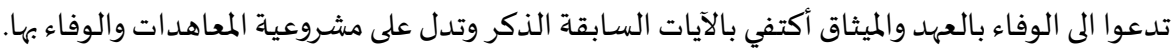

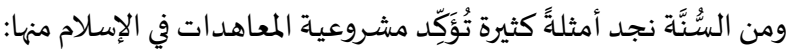

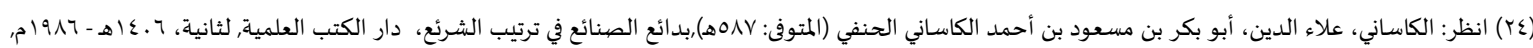

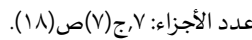

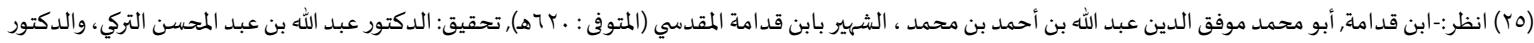

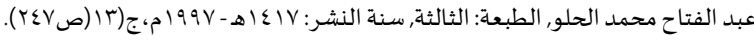

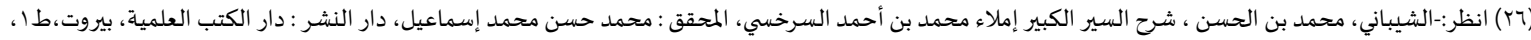

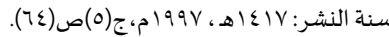

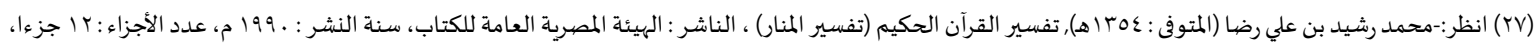
(1)

( (1) انظر:-الزحيلي ، الدكتور وهباه الزحيلي بحث منشور في كلية الشربعة والقانون، أحكام المعاهدات في الشربعة الإسلامية، في جامعة الأمارات، الموجود على شبكة الأنترنت(ع).

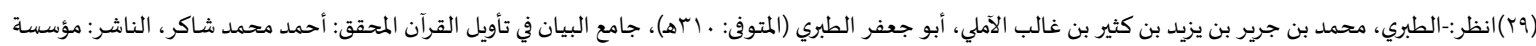

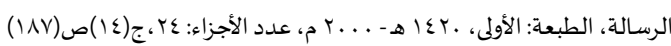

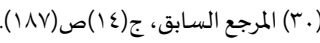

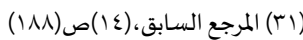

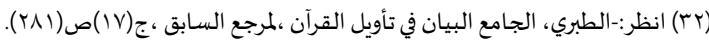

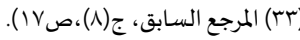

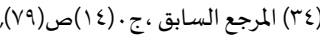


فقد وردت كثير من الاحاديث التي حثت على حفاظ حقوق المعاهد والوفاء بالعهود ومواثيق الصلح منها الحديث الذي رواه ابو أليو

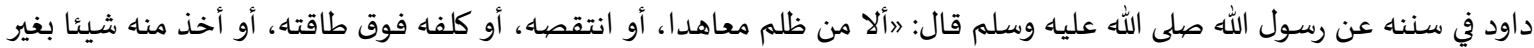

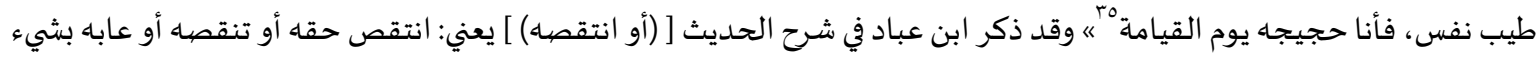

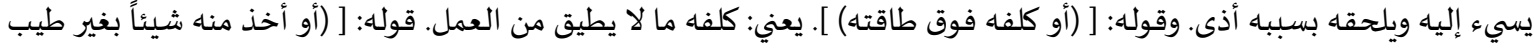

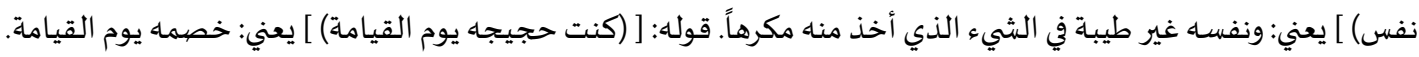

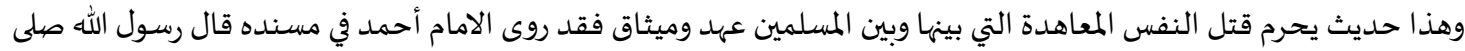

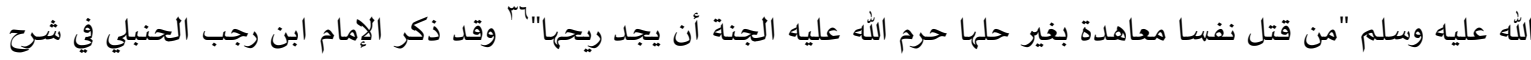

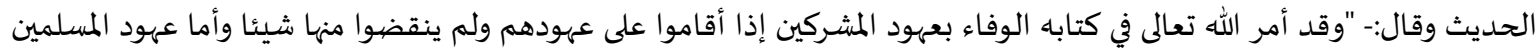

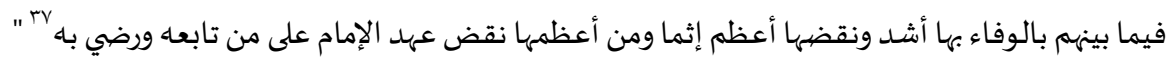

المطلب الثالث: معنى الصلح والمصطلحات ذات الصلة به.

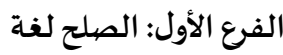

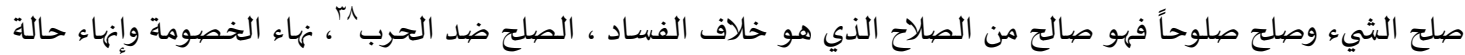

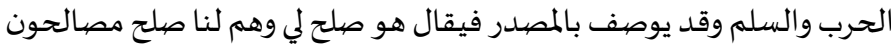

الفرع الثاني: الصلح اصطلاحاً عرفه ابن قدامة حيث قال: "لصلح معاقدة يتوصل بها إلى الإصلاح بين المختلفين ، ويتنوع أنواعا ؛ صلح بين المسلمين وأهل الحرب

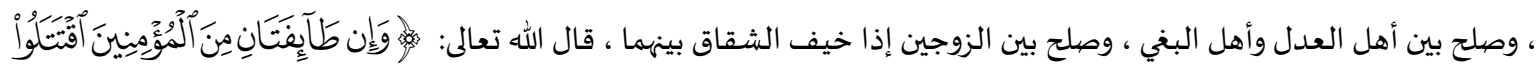

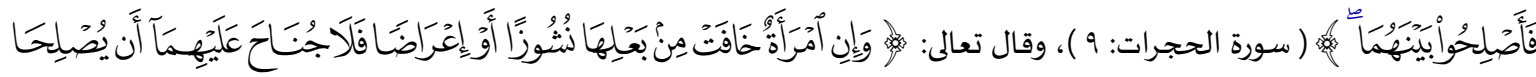

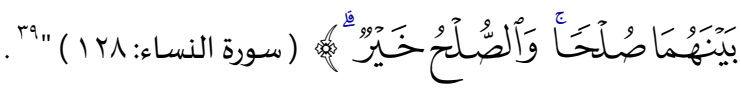

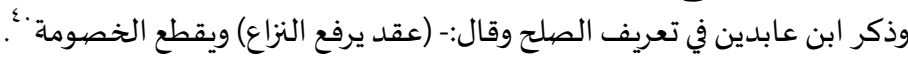

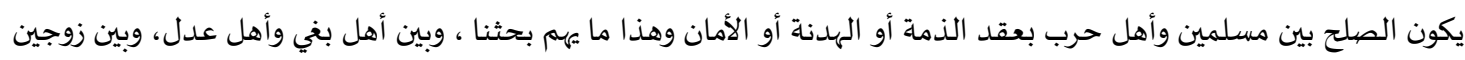

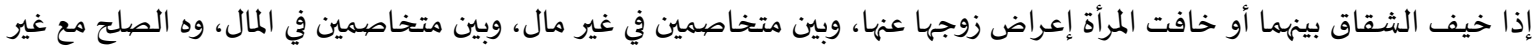

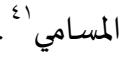
الفرع الثالث: المصطلحات ذات الصلة بالصلح. تعريف الجزية والأمان والمعاهدة لغة واصطلاحا: الجزية في اللغة

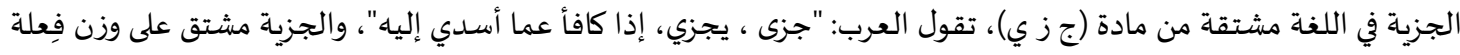

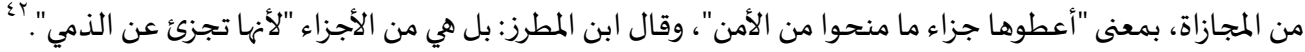

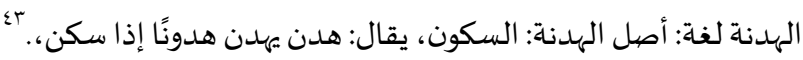

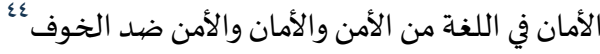

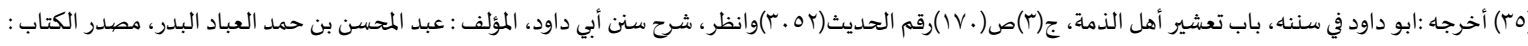

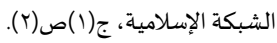

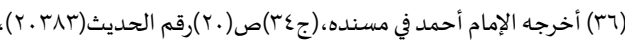

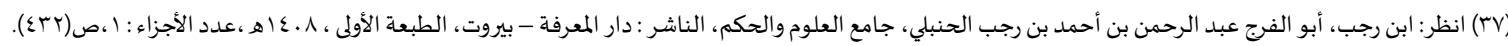

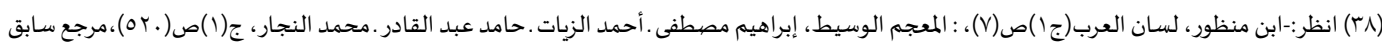

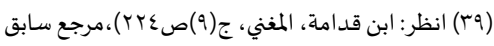

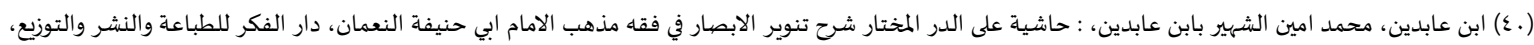

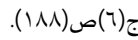

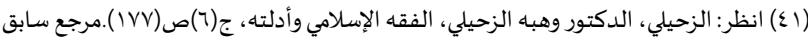

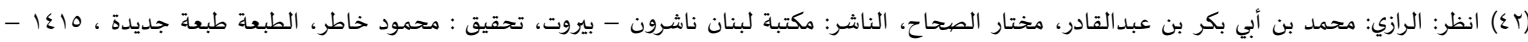
( 1990

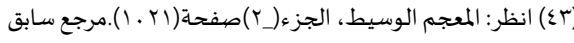
المجلة الدولية للدراسات الإسلامية المتخصصية- المجلد؟، العددr- 19 ـr، ص: r 9-110 
الجزية اصطلاحا:

وقد اختلفت وجهات نظر الفقهاء في تعريف الجزية اصطلاحا تبعا لاختلافهم في طبيعتها , وفي حكم فرضها على المغلوبين الذين

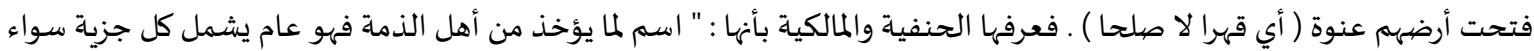

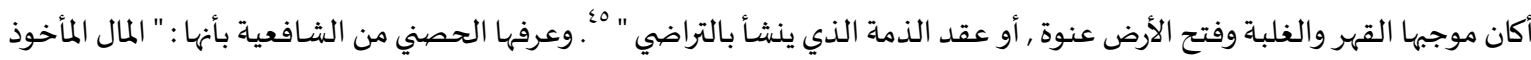

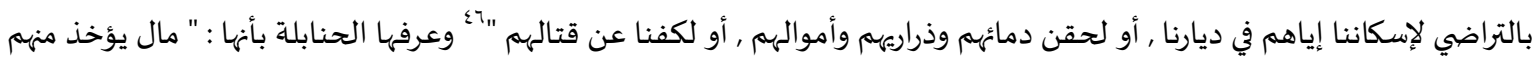

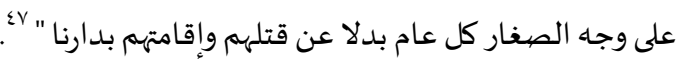

الأمان اصطائاحا:

وفي اصطلاح الفقهاء عرّفه ابن عرفة المالكي بقوله: " رفع استباحة دم الحربي ورقه وماله حين قتاله أو العزم عليه مع استقراره

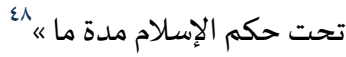

بم يتحقق الأمان؟

يتحقق إما بلفظ الأمان كقولك: أمنتكم أو أعطيتكم الأمان أو ما يجري مجراها من الألفاظ مما يؤدي معناها ويتحقق بالكتابة

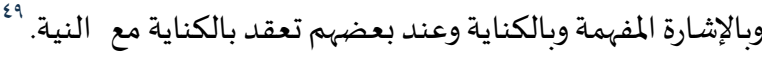

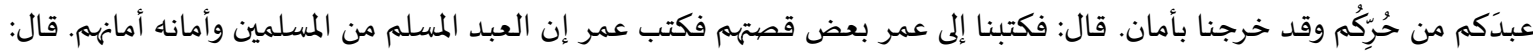

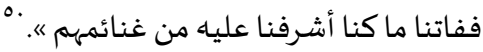

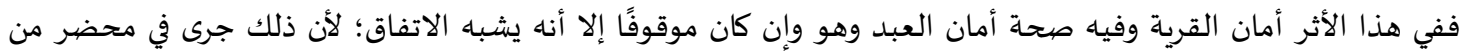
الصحابة ولم يعلم له مخالف. وخلاصة ذلك أنه ليس هناك عدد يمكن حصره في هذا النوع ممن يصح تأمينه من الكفار ولكن ضابط ذلك ما ذكره النووي بقوله: "

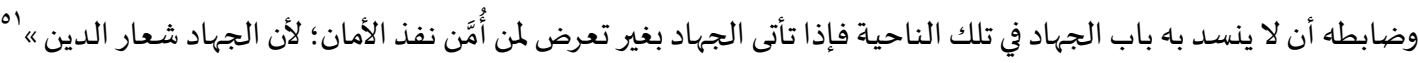

الفرع الثالث: الهدنة اصطلاحا:

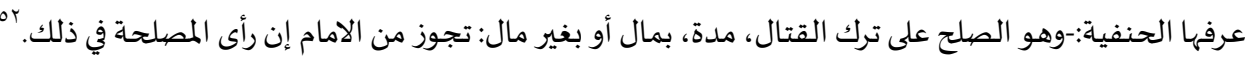

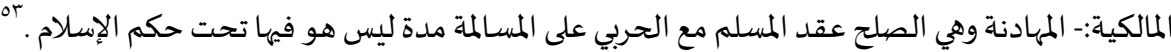

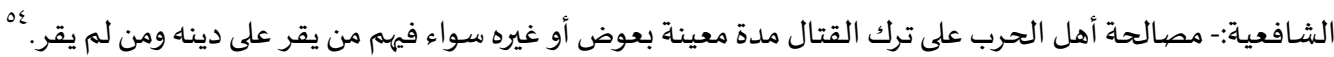

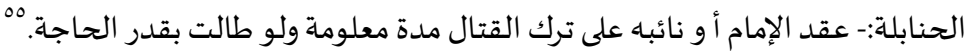

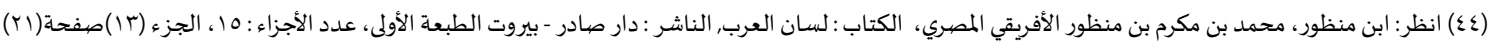

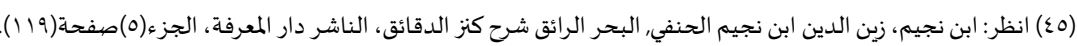

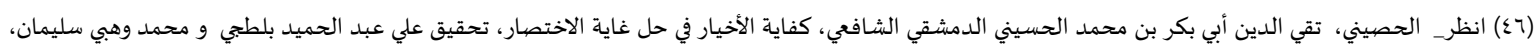

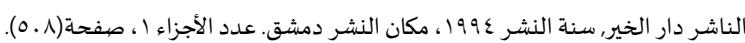

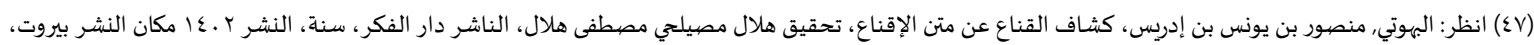

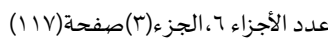

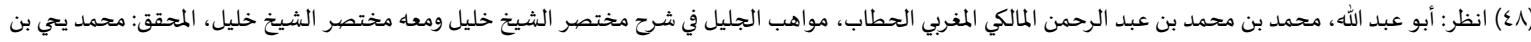

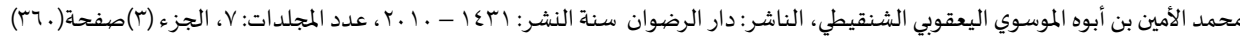

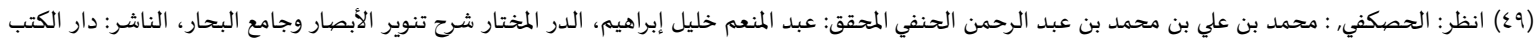

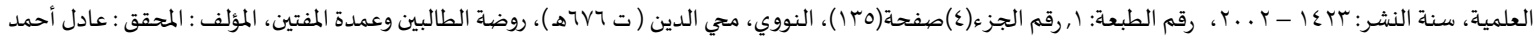

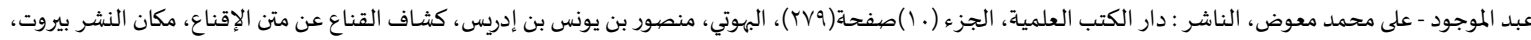

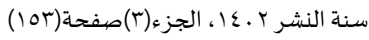

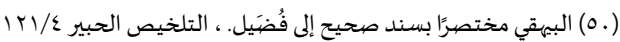

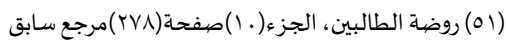

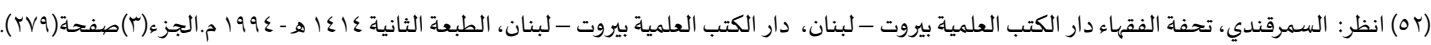

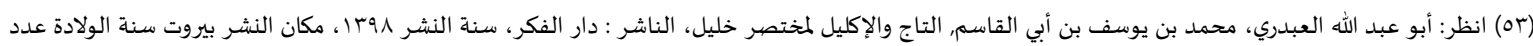

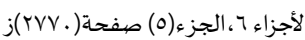

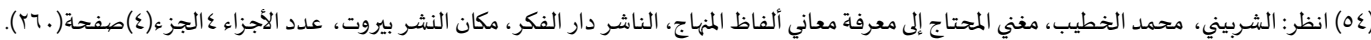

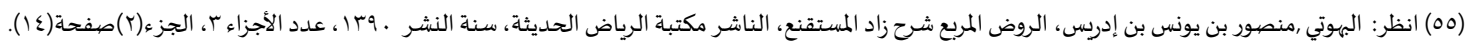




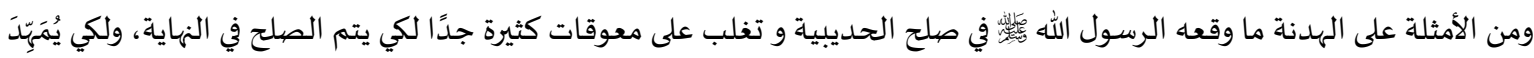

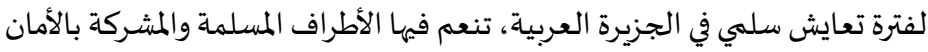

\section{المبحث الثالث: صلح الحديبية وفيه خمسة مطالب}

المطلب الأول: التعريف بصلح الحديبية

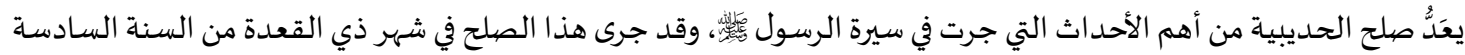

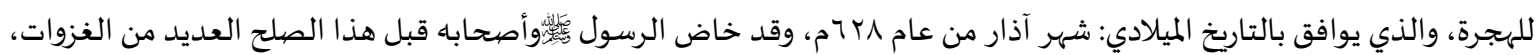

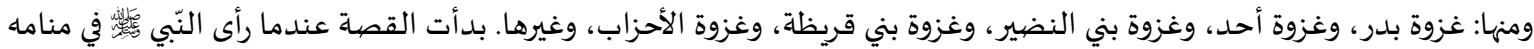

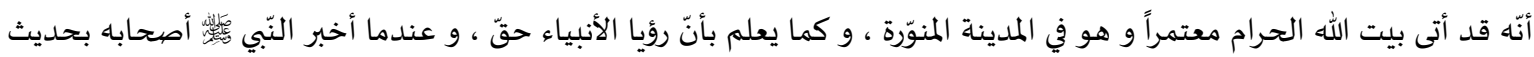

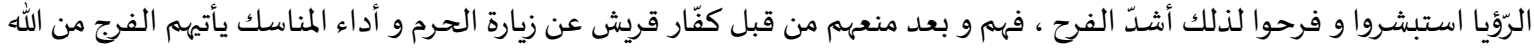

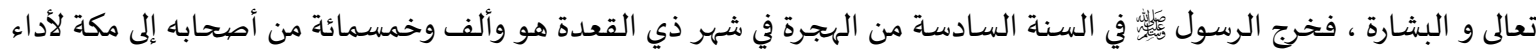

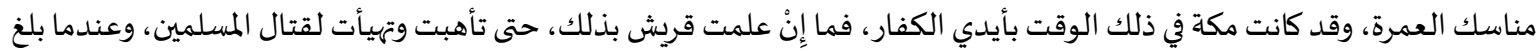

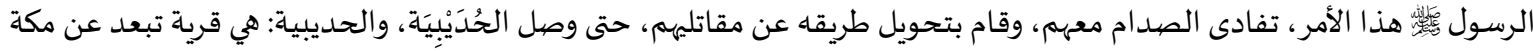

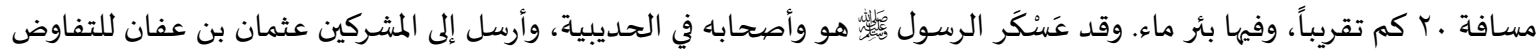

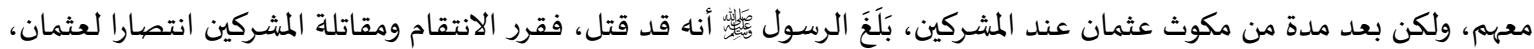

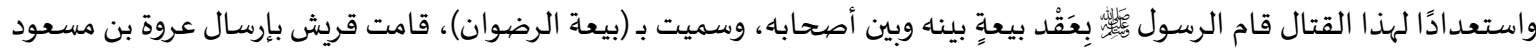

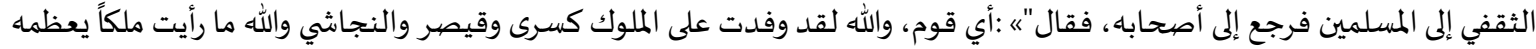

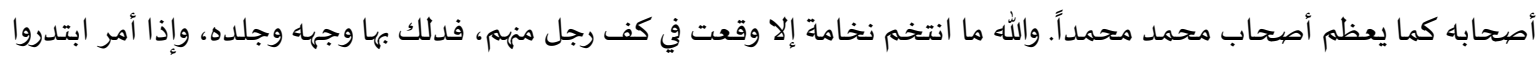

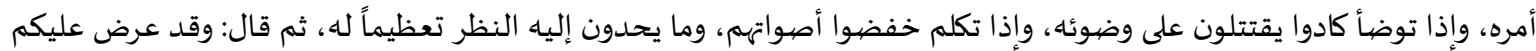

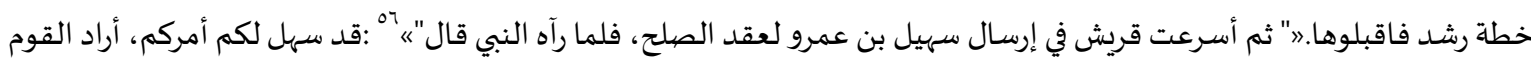

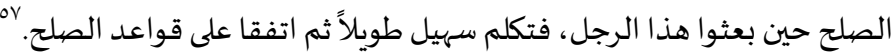

المطلب الثاني: سورة الفتح وصلح الحديبية :-وفيه ثلاثة فروع تمهيد:

الفرع الأول: رؤيا النبي

رأى النبي عليه الصلاة والسلام أخبر أصحابه الكرام أنَّهَ رأى في النوم أنه دخل مكَّة.

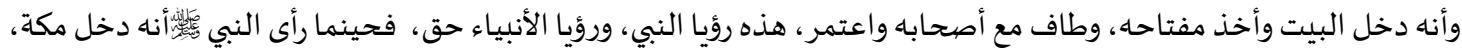

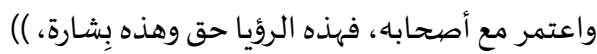

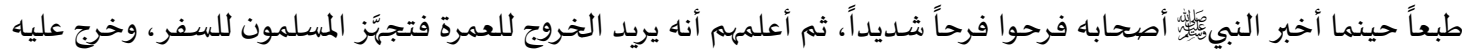

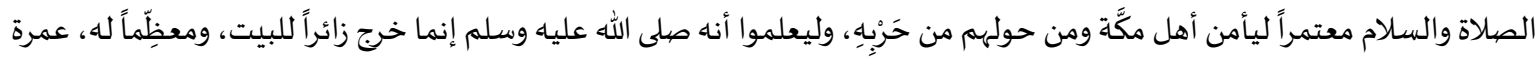

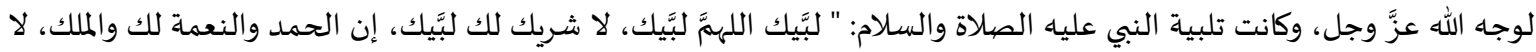

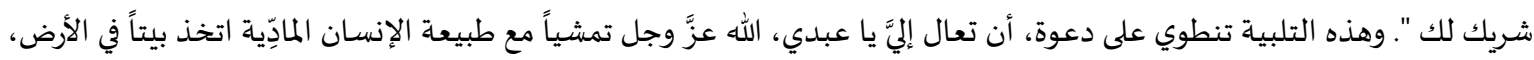

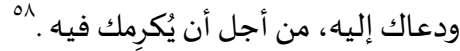

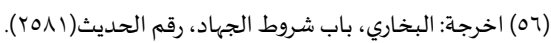

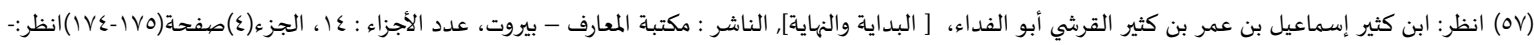

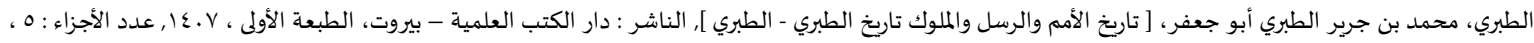

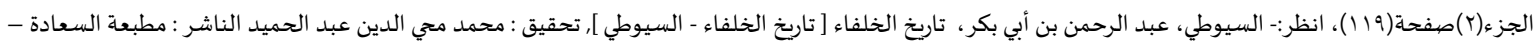

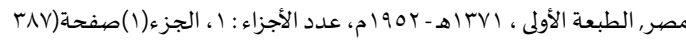

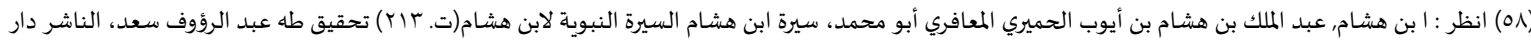

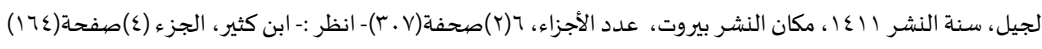




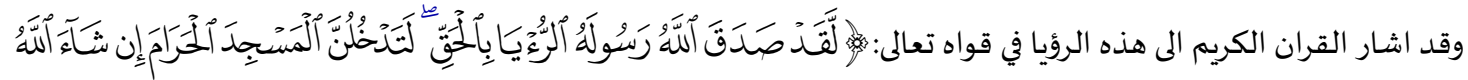

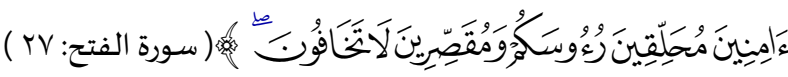

الفرع الثاني: تخلف المنافقين عن الرسول

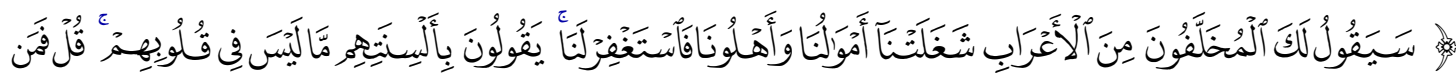

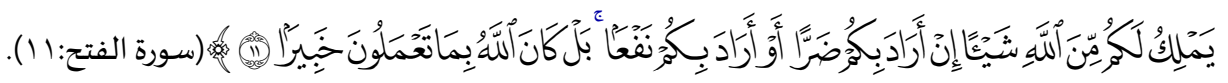

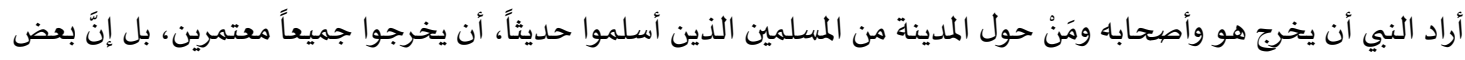

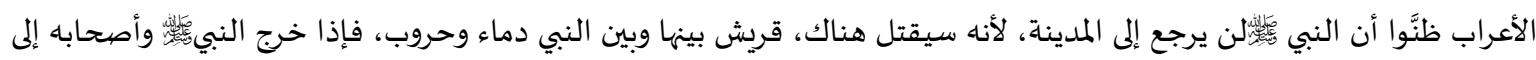

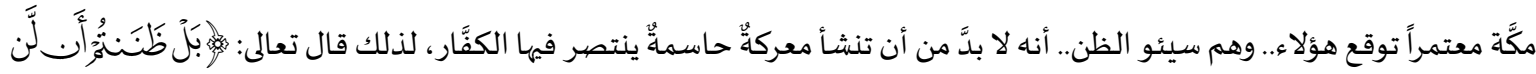

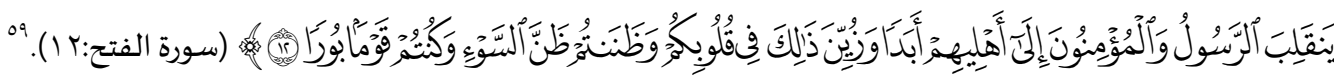
الفرع الثالث:- إظهارحسن النو ايا من قبل الرسول إنس في ذهابه إلى أداء العمرة.

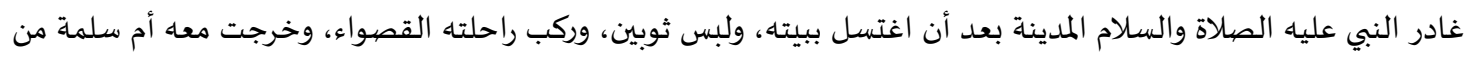

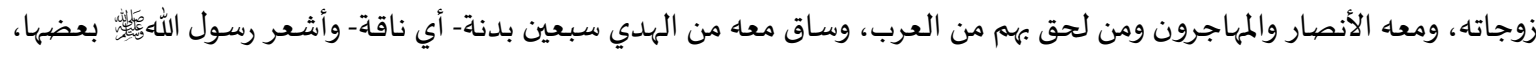

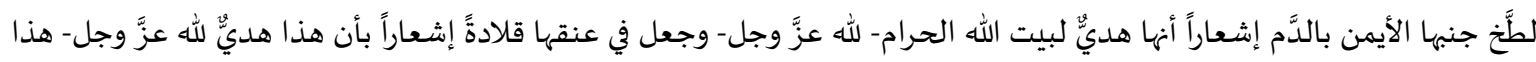

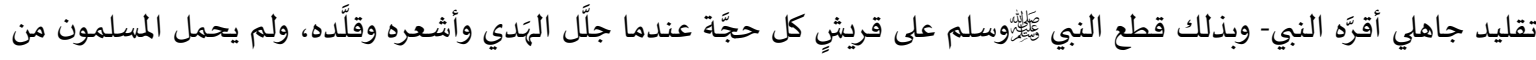

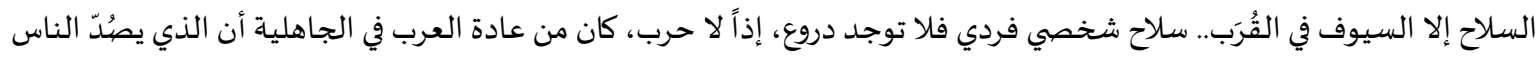

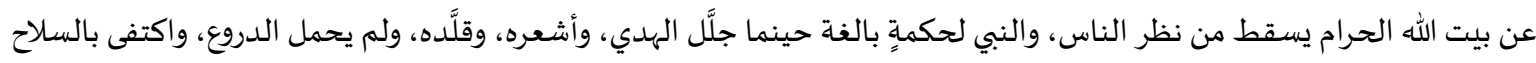

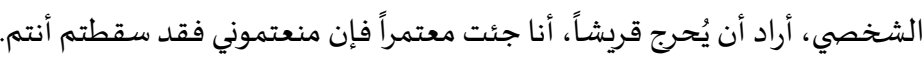

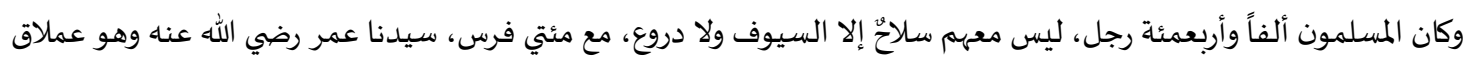

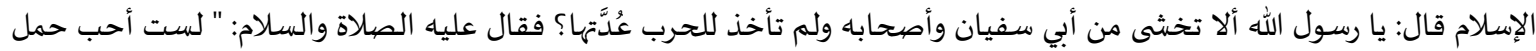

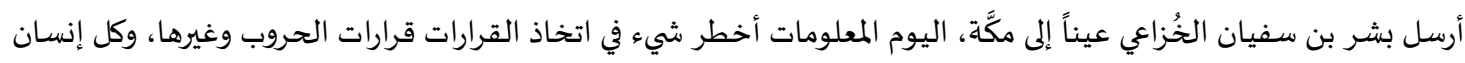

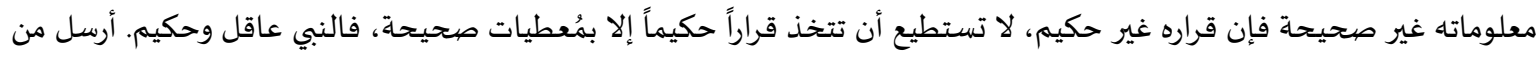

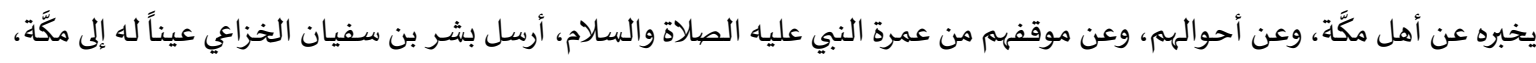

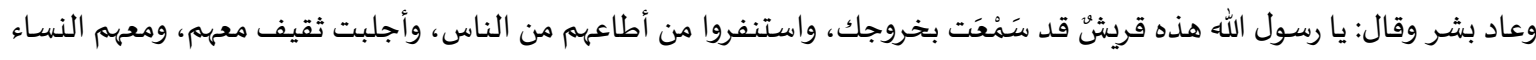

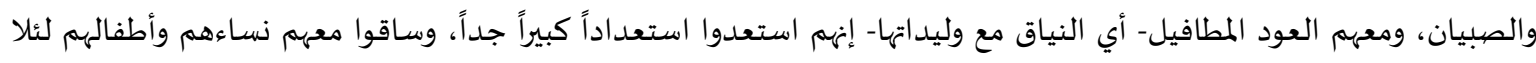

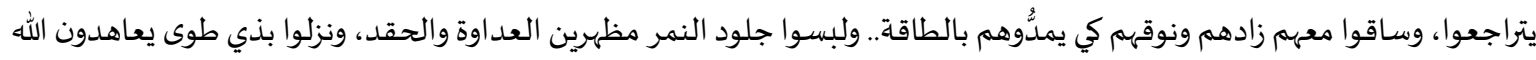

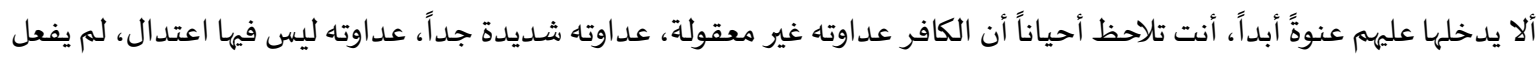

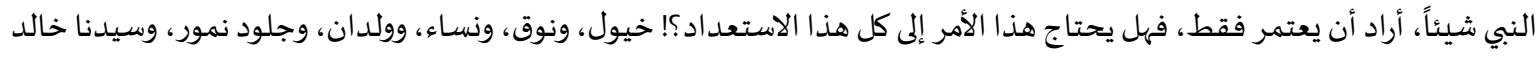

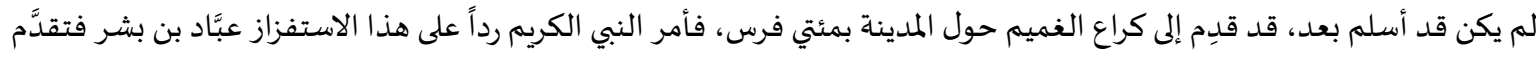

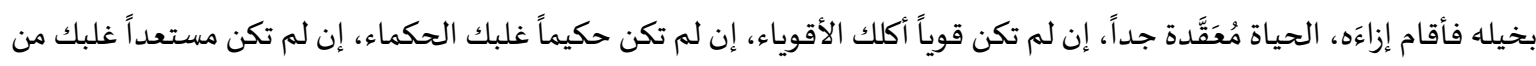

المطلب الثالث: مراحل صلح الحديبية، ومقارنة بالمعاهدات الدولية

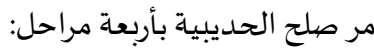

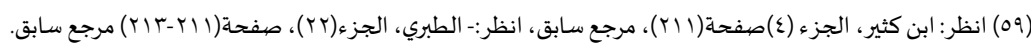

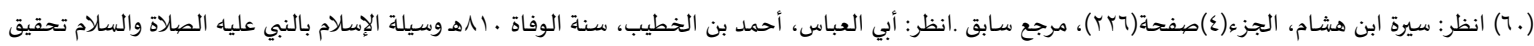

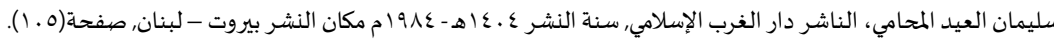

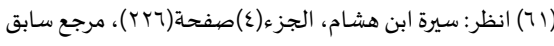


أولاً: مرحلة التفاوض والتحفظات:

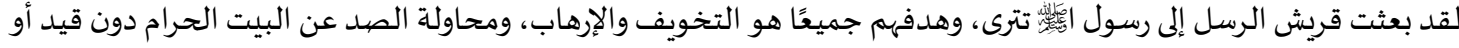

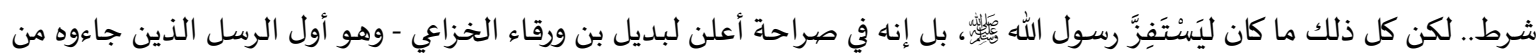

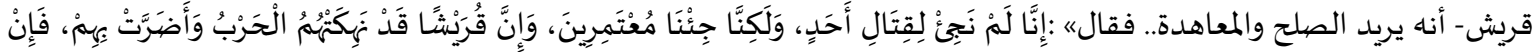

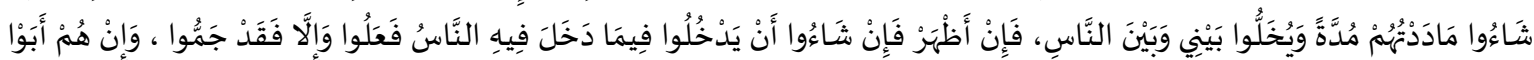

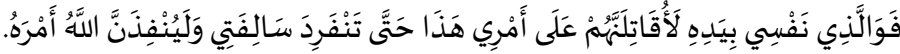

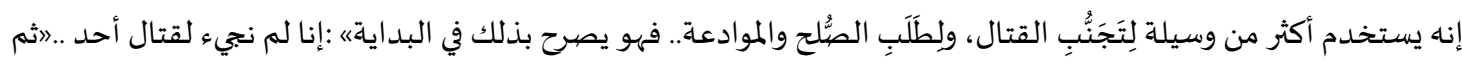

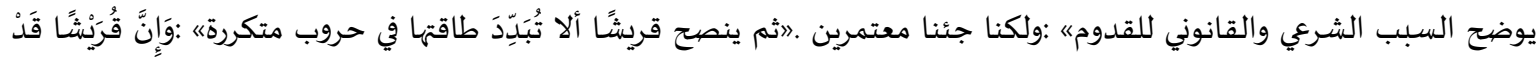

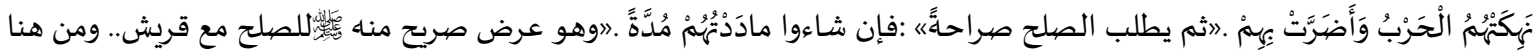

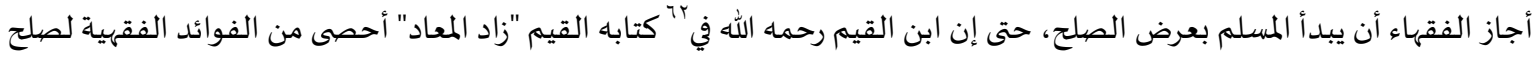

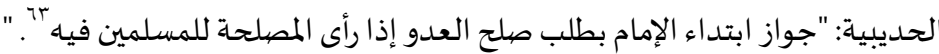

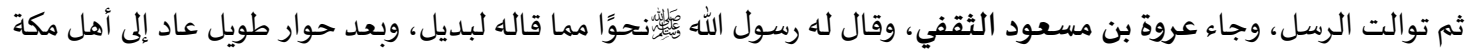

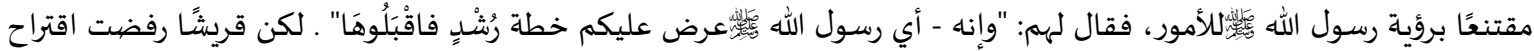

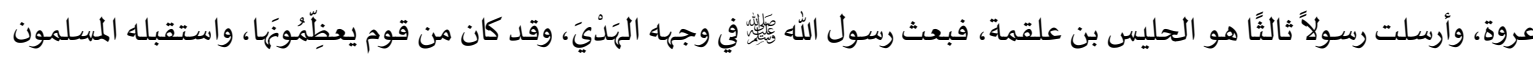

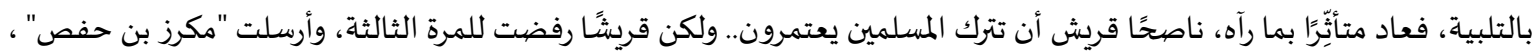
فلم يصل إلى نتيجة أخرى.

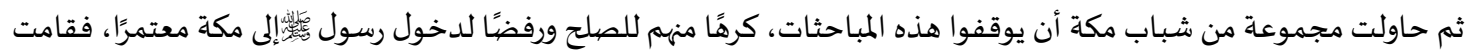

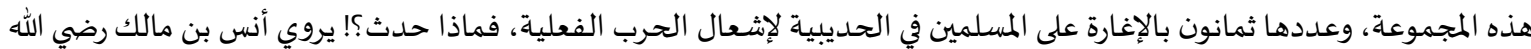

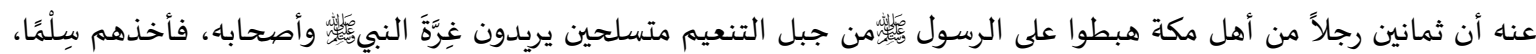

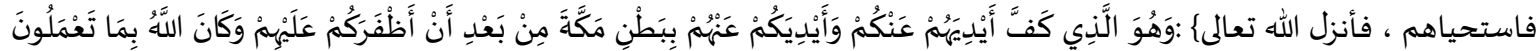

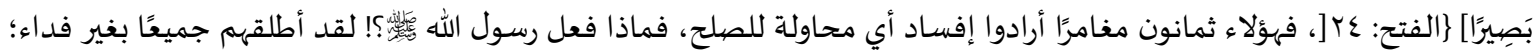
وذلك إثباتًا لحسن النوايا، وسلامة الصدر.

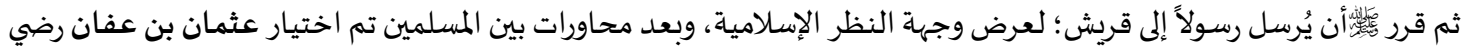

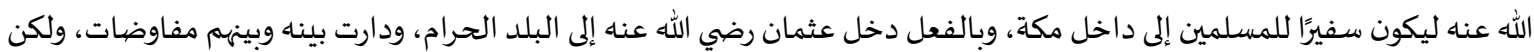

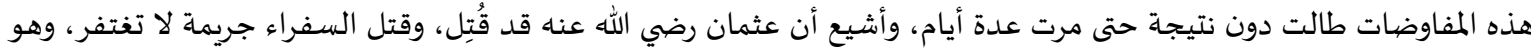

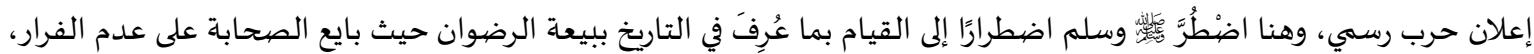

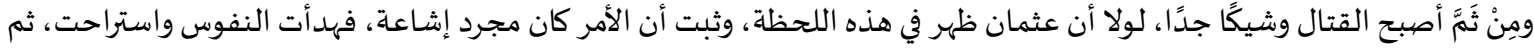

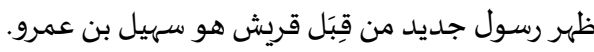

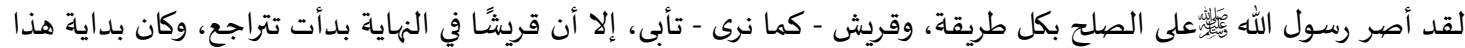

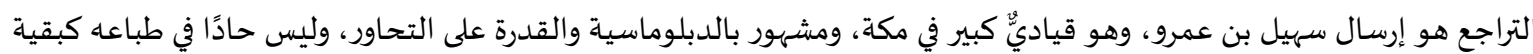

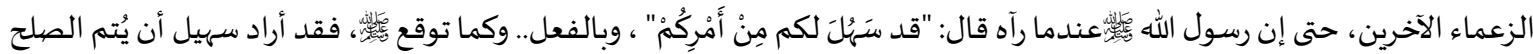

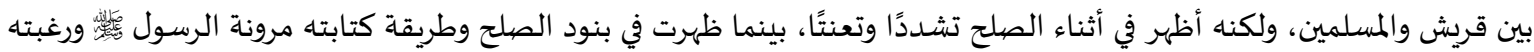

(Tr) انظر: ابن قيم، محمد بن أبي بكر بن أيوب ابن قيم الجوزية، زاد المعاد في هدي خير العباد المحقق: شعيب الأرناؤوط - عبد القادر الأرناؤوط, الناشر: مؤسسة الرسالة، سنة

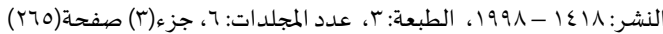

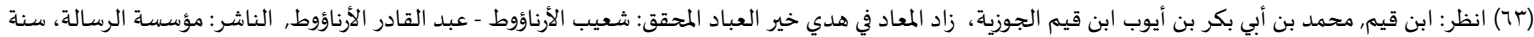

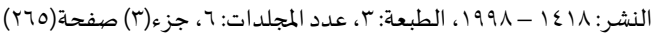




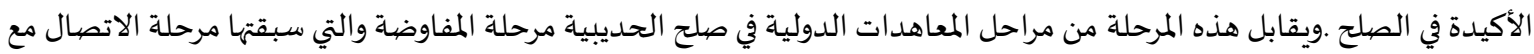

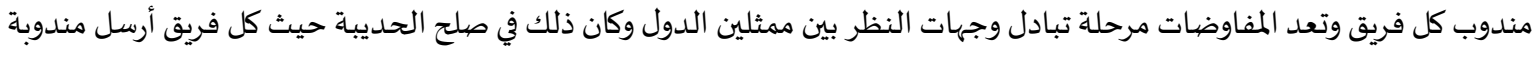
للتفاهم

ثانياً: مرحلة تحربر المعاهدة إقرارها

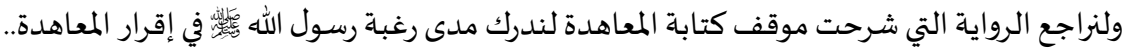

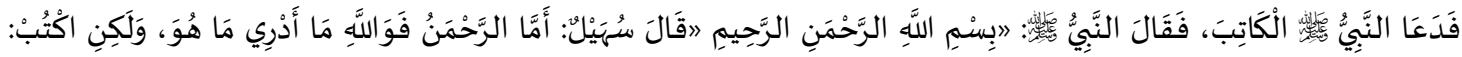

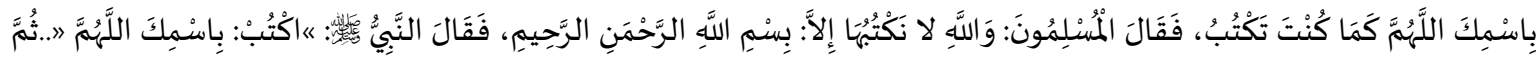

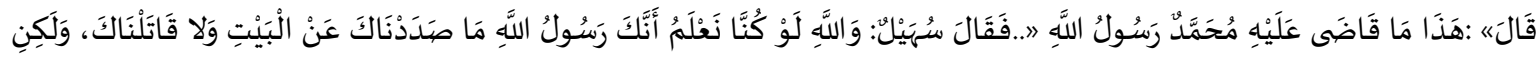

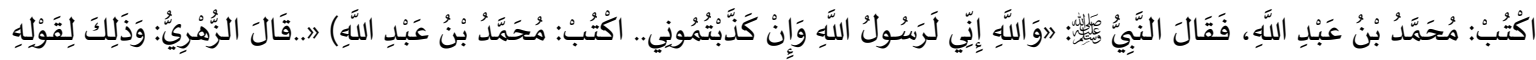

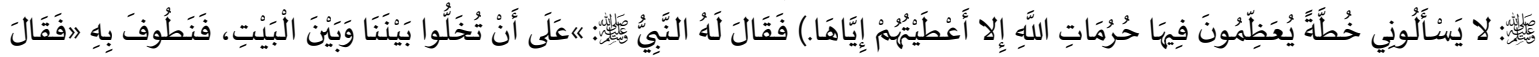

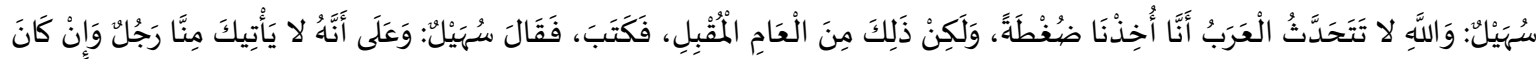

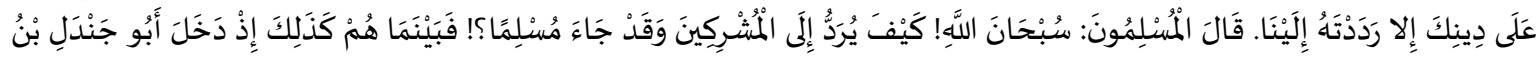

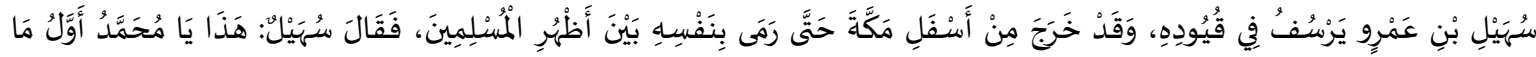

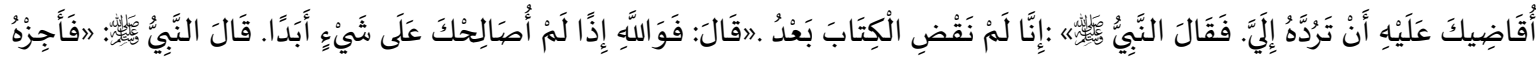

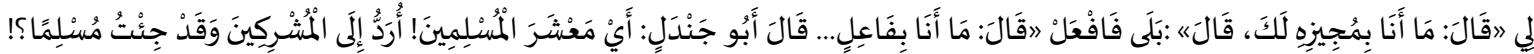

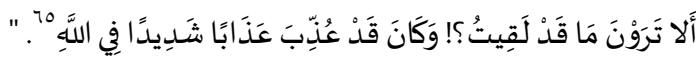

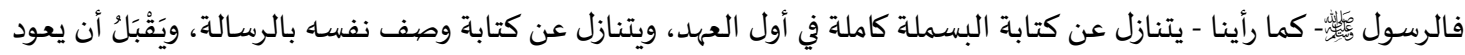

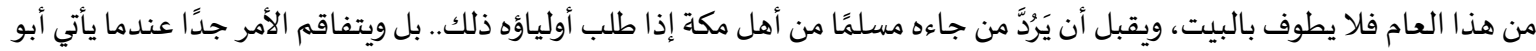

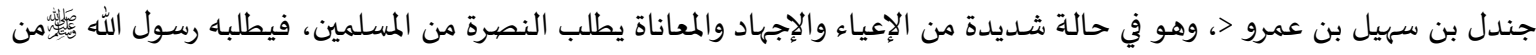

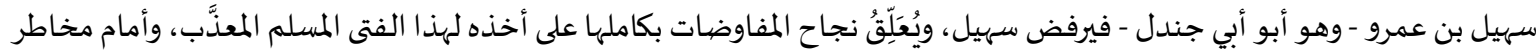

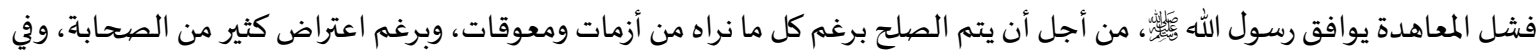
مقدمتهم عمر بن الخطاب رضي الله عنه.

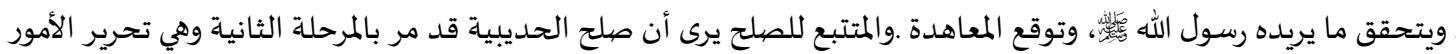

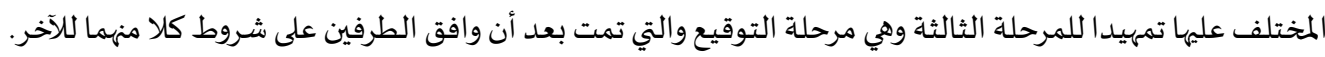

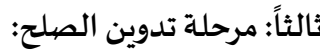

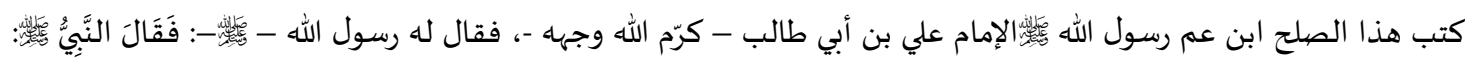

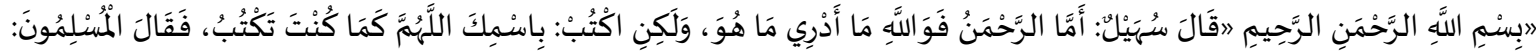

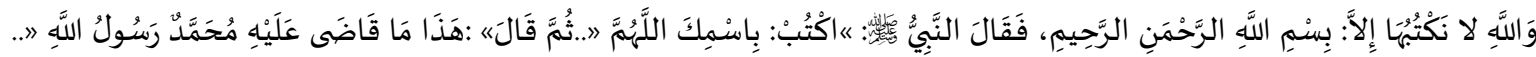

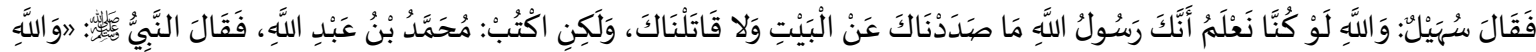

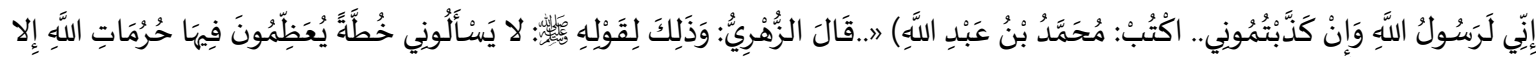

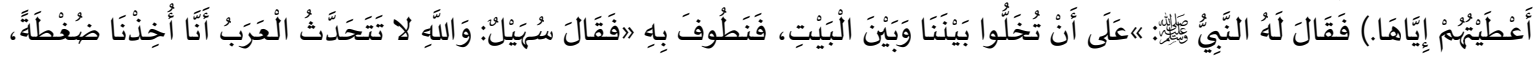

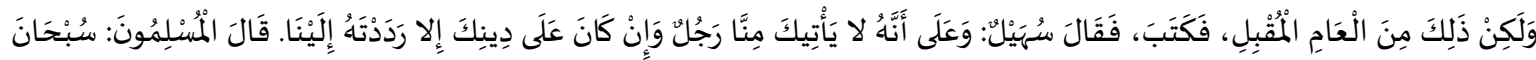

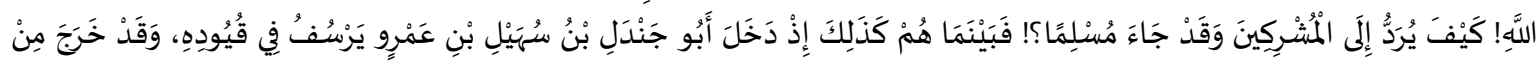

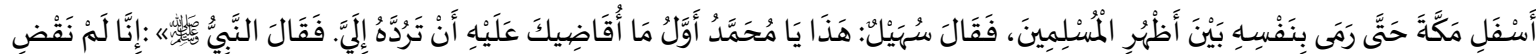

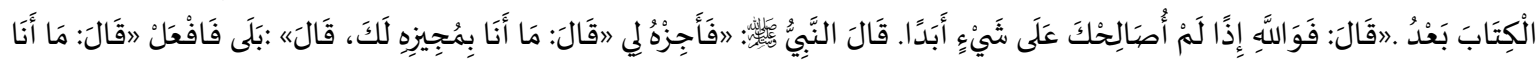

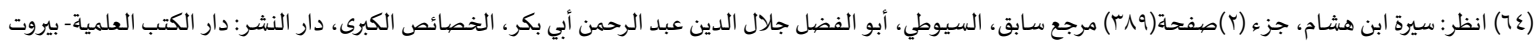

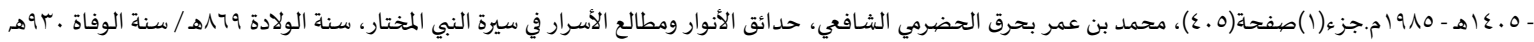

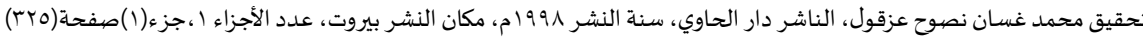

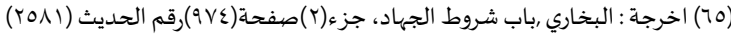




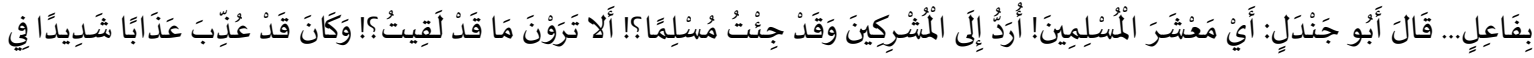

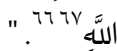

ولإبراز بنود المعاهدة بشكل أوضح نوردها على شكل نقاط:

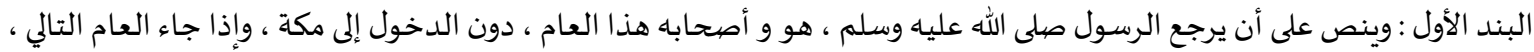

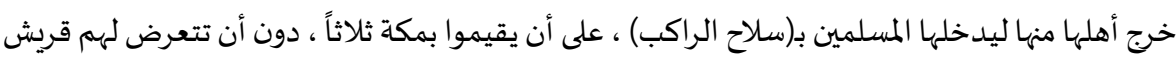

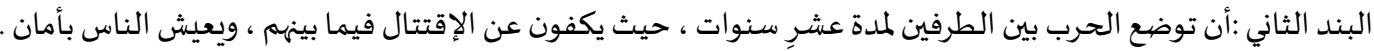

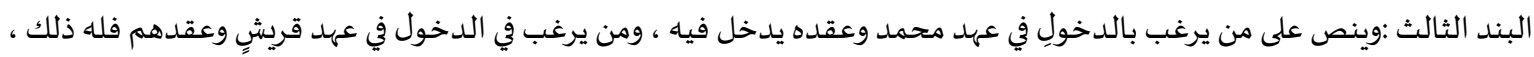

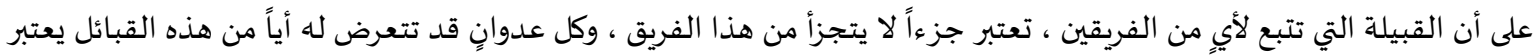

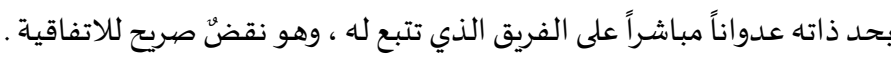

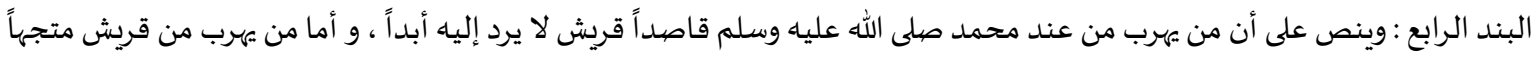

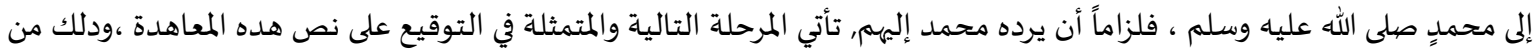

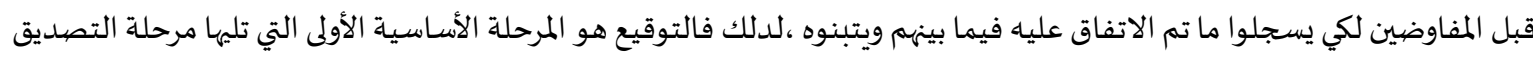
الدستوري ويعبر التوقيع عن رضا المفاوضين ، ولا يعني أن المعاهدة أصبحت بدلك نافدة حيث أن التوقيع في المعاهدات الثنائية يفترض موافقة الطرفين. رابعاً: مرحلة التنفيذ:

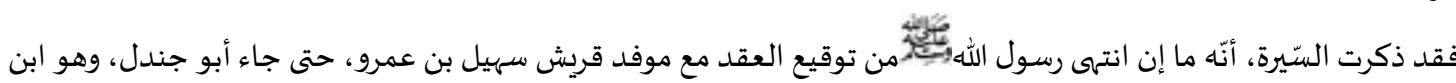

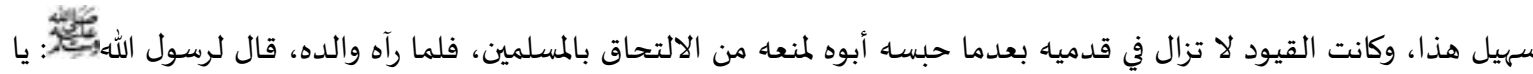

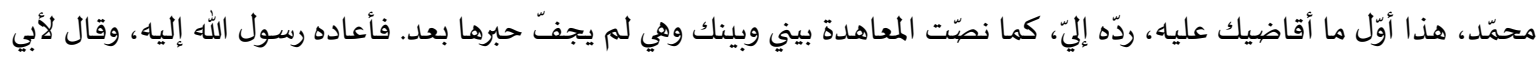

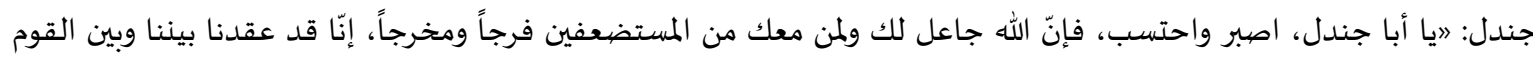

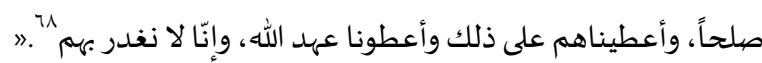

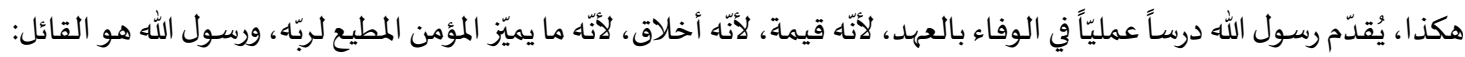

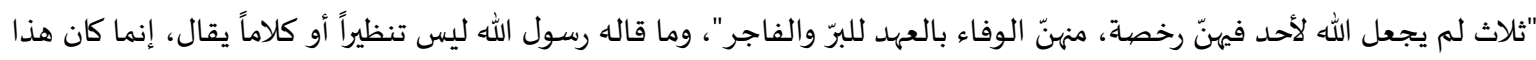

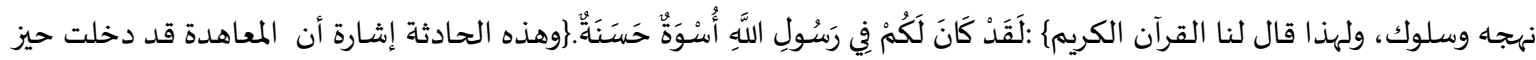
التنفيذ والأخذ بالبنود والعمل على تطبيقها

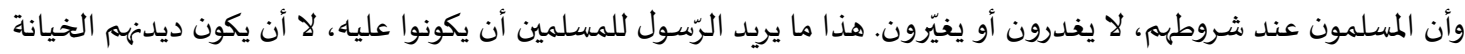

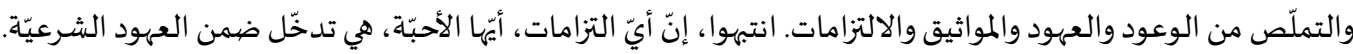

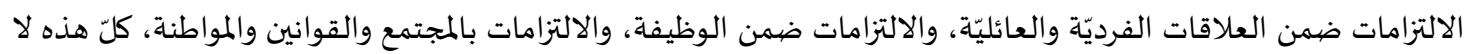

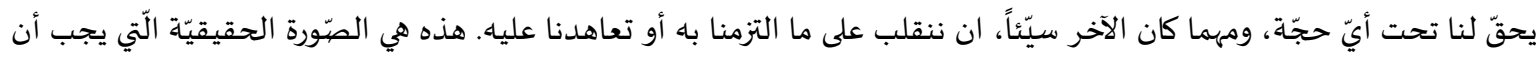

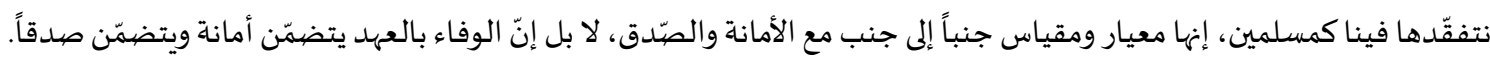

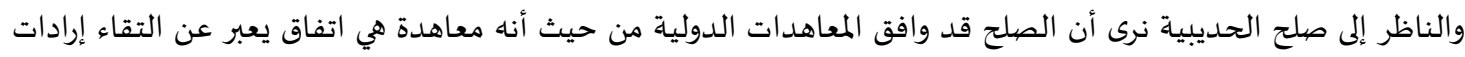

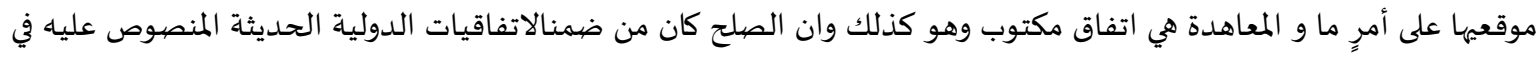

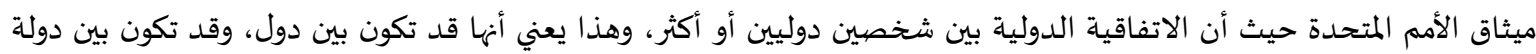

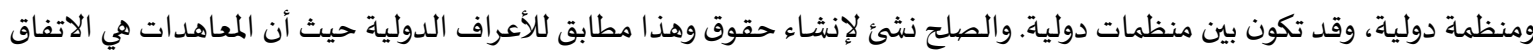

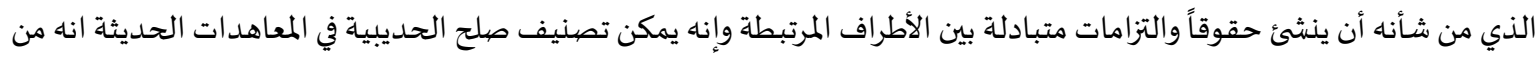

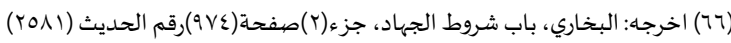

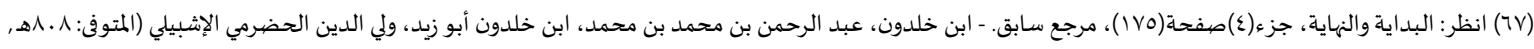

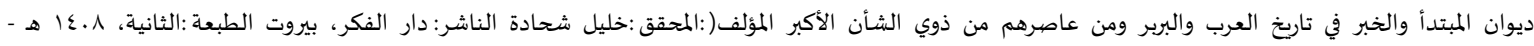

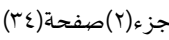

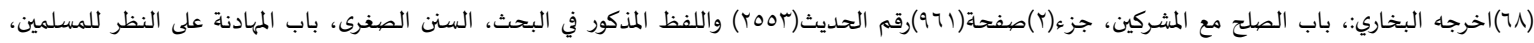

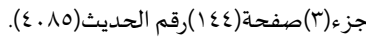


ضهمن معاهدات ثنائية وهذا من حيث أطراف المعادلة حيث كان بين المسلمين وقريش وهما طرفا المعادلة أما من حيث الطبيعة فهي

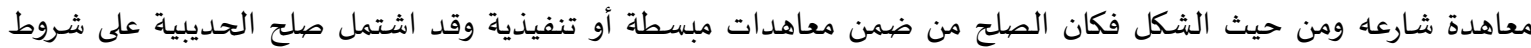

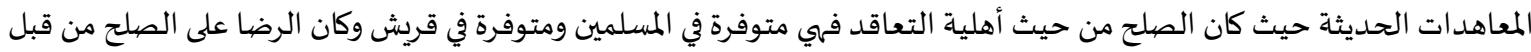

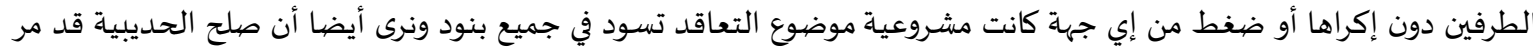
بجميع مراحل إجراءات إبرام المعاهدة من حيث مرحلة التفاوض ومرحلة تحرير المعاهدة ومرحلة التوقيع ومرحلة التصديد إيق والتحفظات

والتسجيل والنشر.

المطلب الر ابع : وقفة مع اتفاقية الصلح، وفيه ثلاثة فروع:

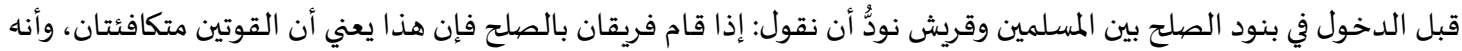

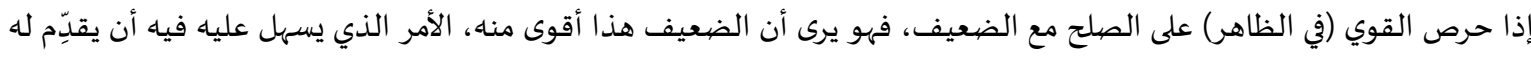

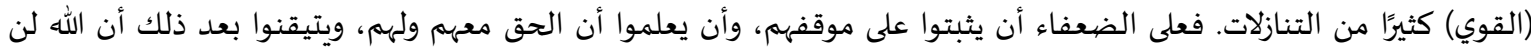
يخذلهم، وأن هذا مما يزلزل كيان الكافرين.

وفي تجسيد لهذا الدور فقد جلس القرشيون مع ما لهم من تاريخ وقوة وجنود وأحلاف، جلسوا مع الجمانداعة الضعيفة المستضعفة، تلك التي كانت تعيش عندهم، ثم هاجرت من ديارهم إلى المدينة المنورة، وقد جاءت تريد العُمْرة وهي بسلاح المسافر.

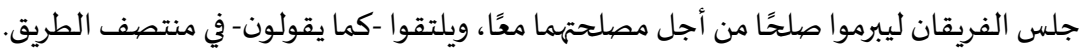
الفرع الأول: إيجابيات معاهدات الصلح

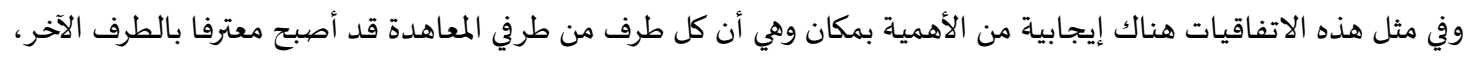

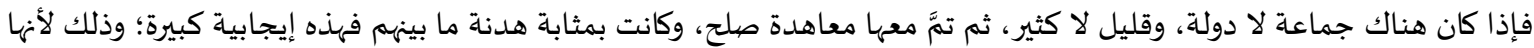

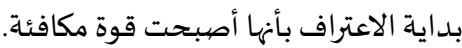

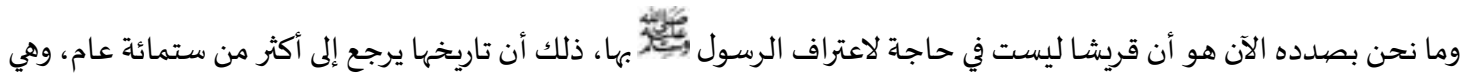

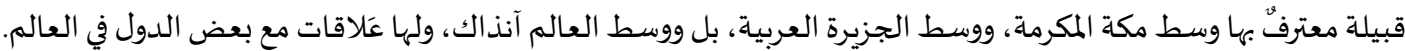

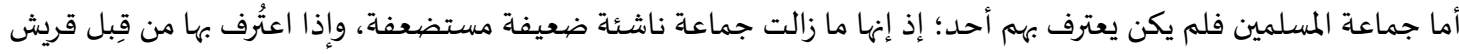

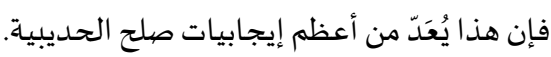
ولعل أكبر دليل على ذلك ما نراه في أيامنا هذه، إذ دعت بعض الدول الديات الكبرى مثل روسيا حركة المقاومة الإسلامية (حماس) -التي

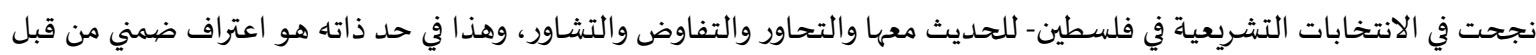
روسيا (من أكبر دول العالم) بشرعية حماس، الأمر الذي لم يكن ليتجاهله اليهود فغضبوا كثيرًا، حتى وإن كان سيتم في هذا التشاور

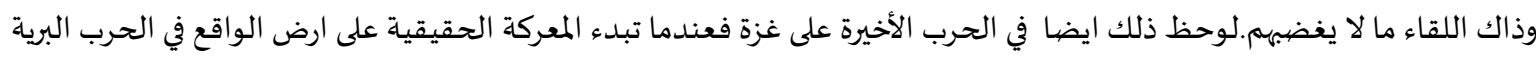

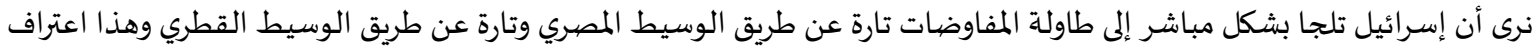

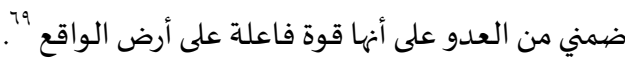

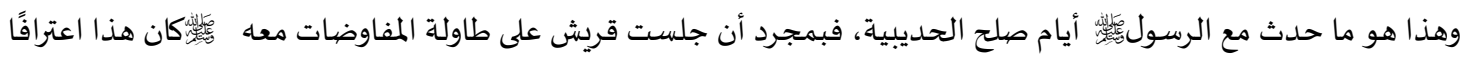

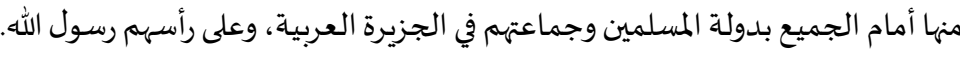

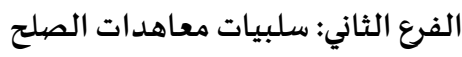
مع وجود الإيجابية السابقة في معاهدات الصلح إلا أن هناك سلبية أيضًا لا بد منها أثناء العقد، وهي أنه إذا جلس طرفان

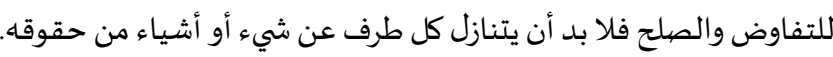
ومثل هذا بحاجة إلى وقفة متأنية، حتى إذا حدث مثل هذا بين المسلمين وبين غيرهم نكون على وعي تام بطبيعة هذا التفاوض وهذا

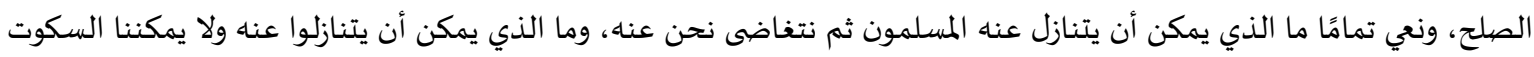
علياء. 
ومن هنا فلا شك أن الرسول كان هذا اعترافًا منها أمام الجميع بدولة المسلمين وجماعتهم في الجزيرة العربية، وعلى رأسهم رسول

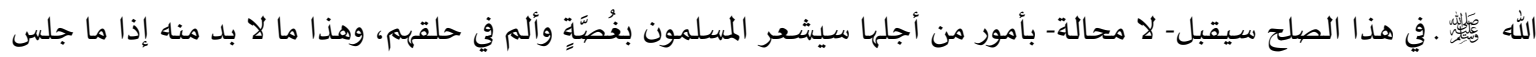

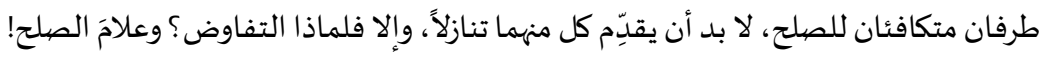

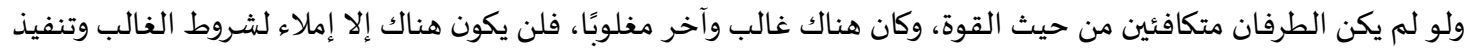

لأوامره، ولن يكون هناك إلا معاهدات استسلام.

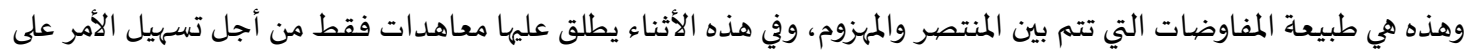

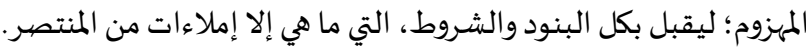

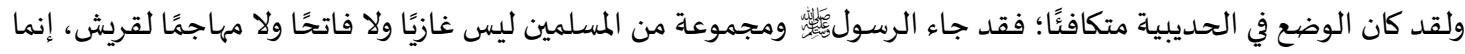

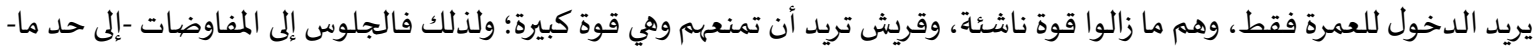

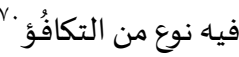
الفرع الثالث: دورالمرأة المسلمة في اتخاذ القراروالمشاركة في الحياة السياسة

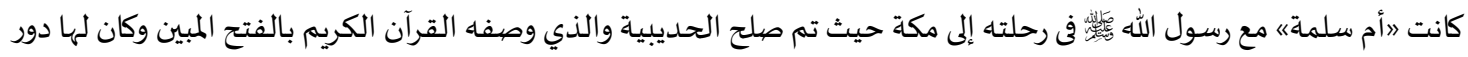

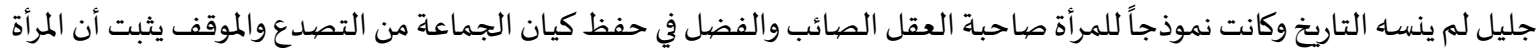

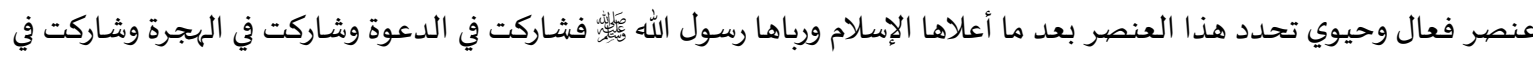

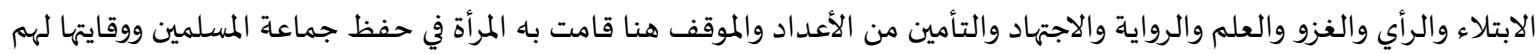
من التدهور إثر الأزمة النفسية التي انتابتهم بعد شروط صلح الحرائ الحديبية وعودتهم للمدينة دون دخول مكة فقد اعتبر المسلمون ما حدث

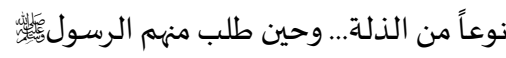

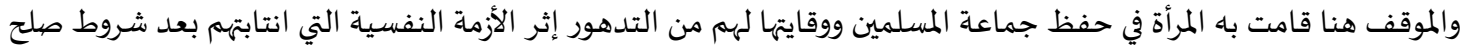

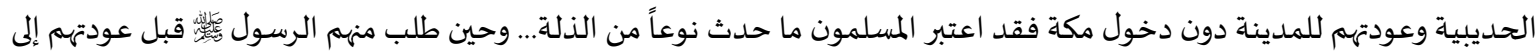

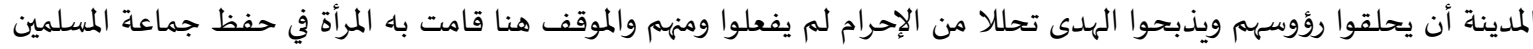

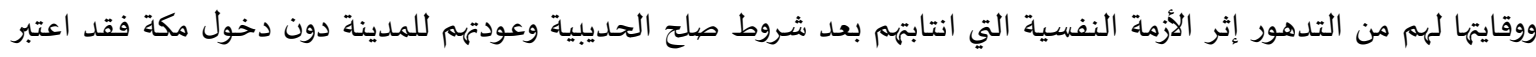

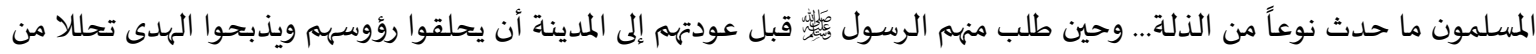

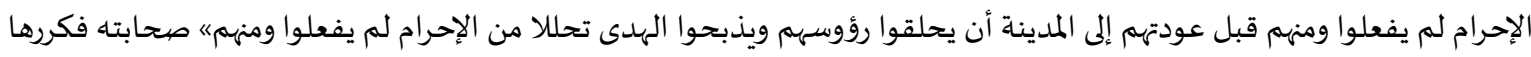

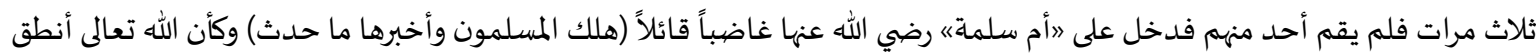

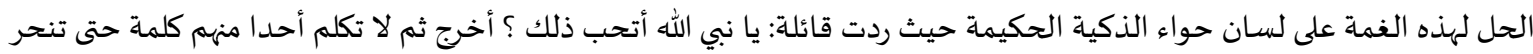

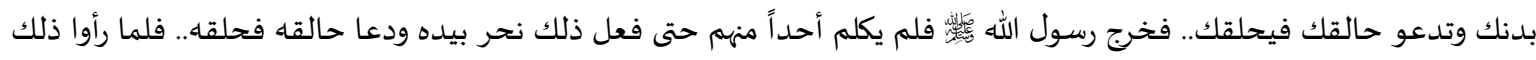
قاموا فنحروا وجعل بعضهم يحلق لبعض. ولعل هذه الحادثة تكون ردا قويا على من يدعي أن الإسلام قد ظلم المرأة ولم يعطها الحق في المشاركة في كل مجالات الحياة .

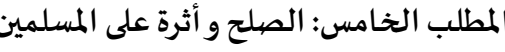

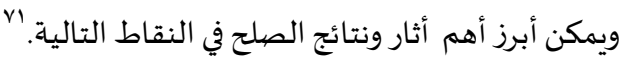

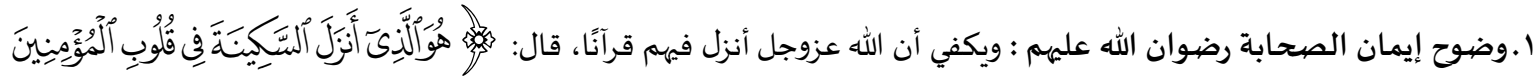

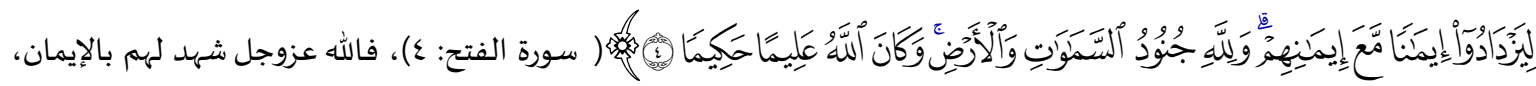
وزيادة الإيمان بعد هذا الحدث العظيم صلح الحديبية.

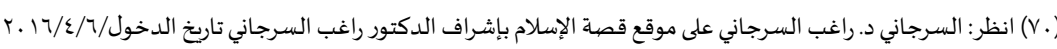

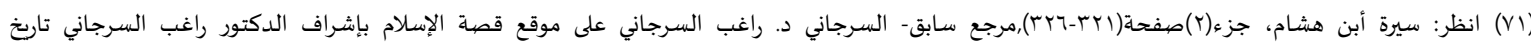

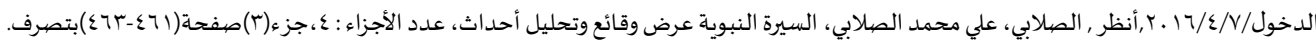




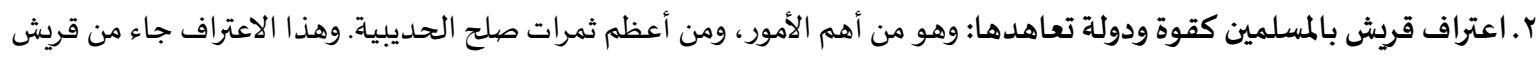

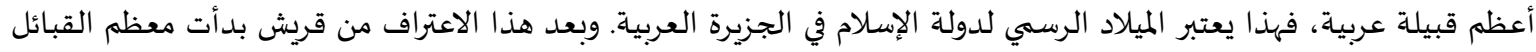

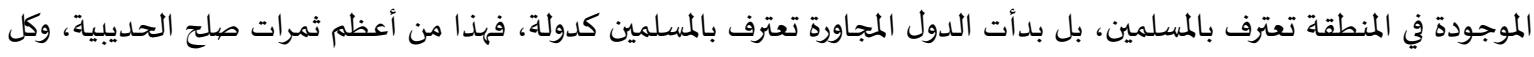

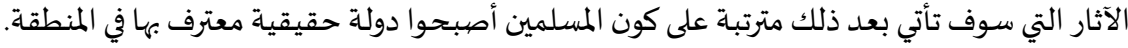

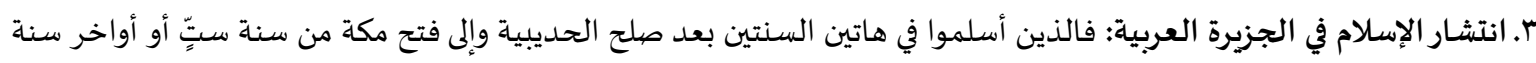

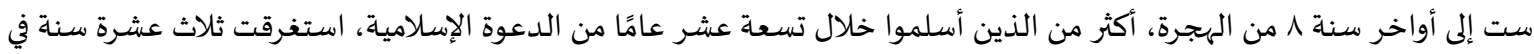

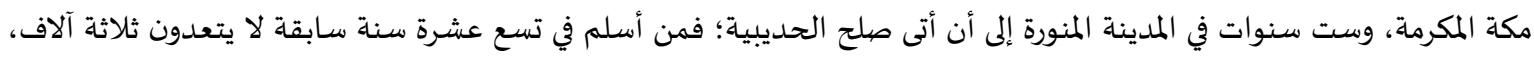

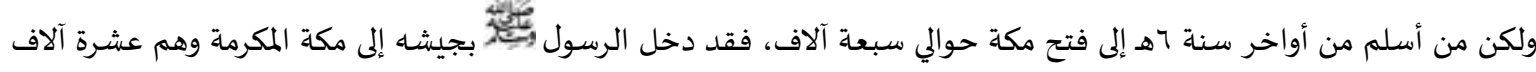

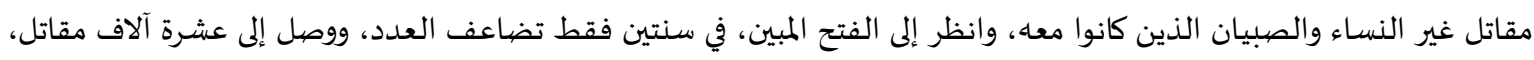
فهذا حقًّا فتح مبين.

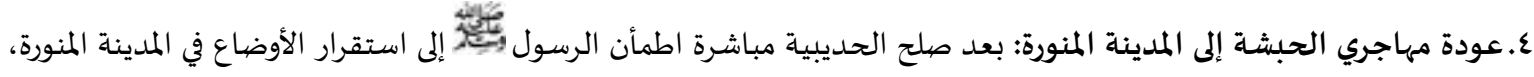

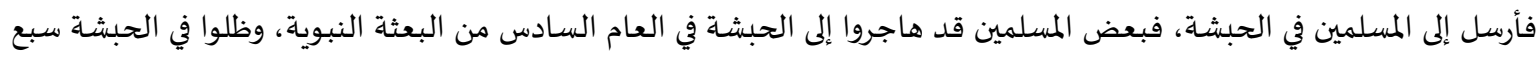

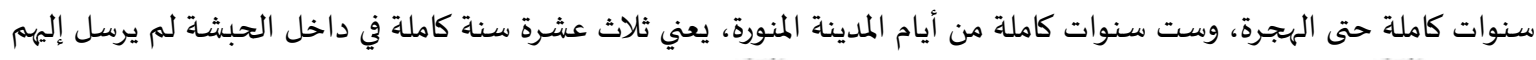

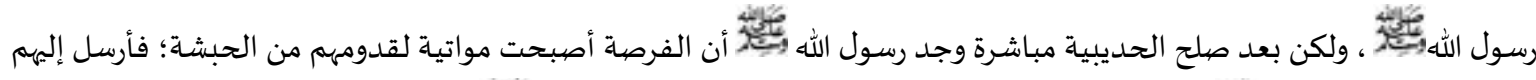

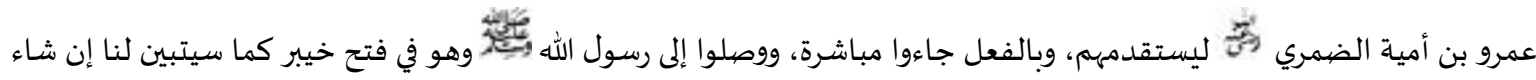

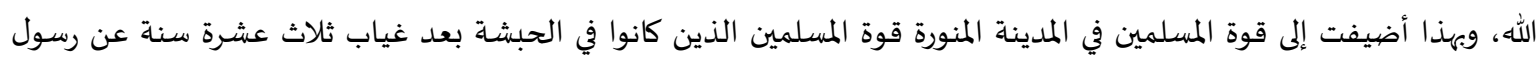
الله. ه. قدوم المسلمين من القبائل المختلفة الأخرى: المسلمون في كل قبائل العرب بدأوا يتحركون منها إلى المدينة المنورة، قبل هذه اللحظة

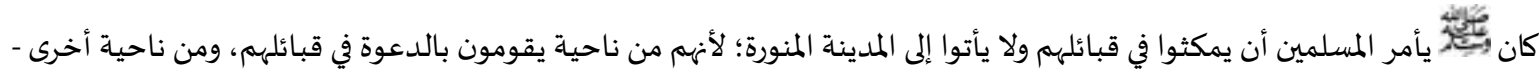

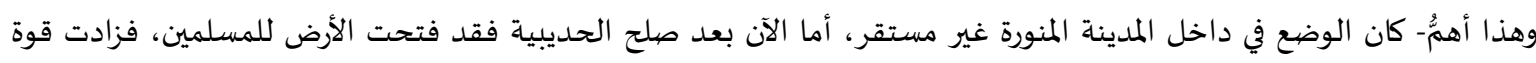

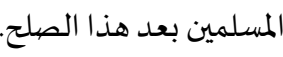
1. تعاهدت قبائل كثيرة مع رسول اللهاءِّ: وما كانت هذه القبائل تجرؤ على هذا الأمر قبل هذا الصلح، وأول هذه القبائل قبيلة خُزَاعة،

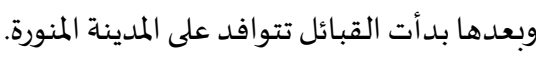
V.بدأت المراسلات النبوية من رسول الله إلى عموم زعماء العالم في كل مكان: فقد راسل كسرى فارس، وقيصر الروم، وزعماء العالم

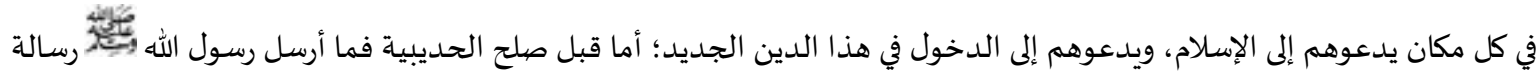

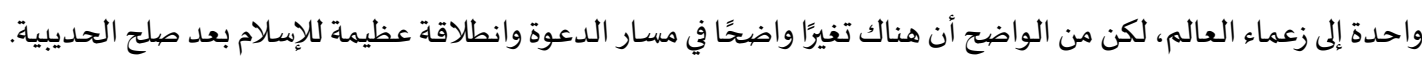

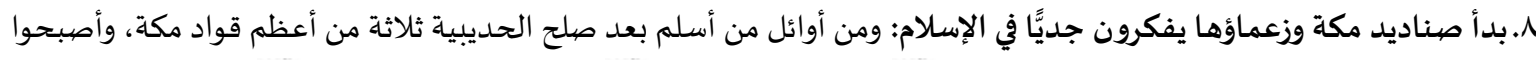

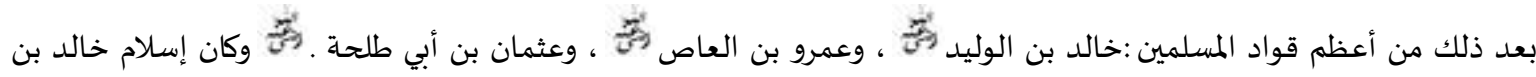

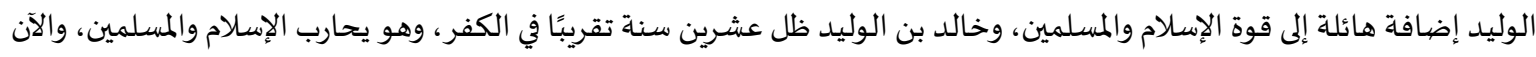

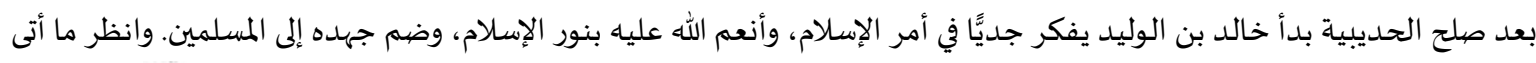

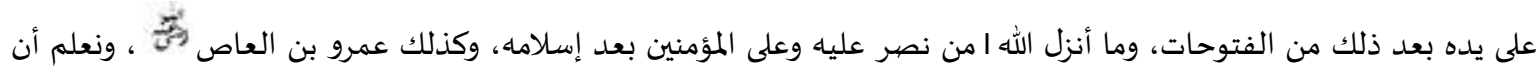

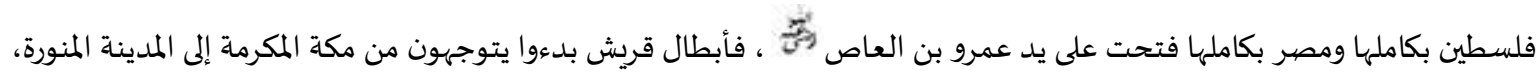
فهو فتح مبين حقًّا.

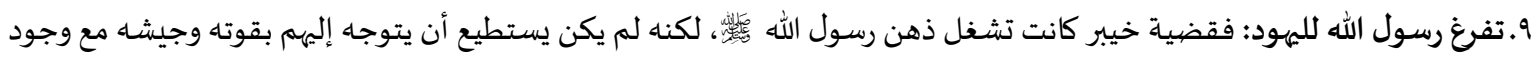

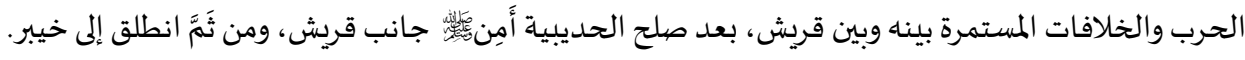

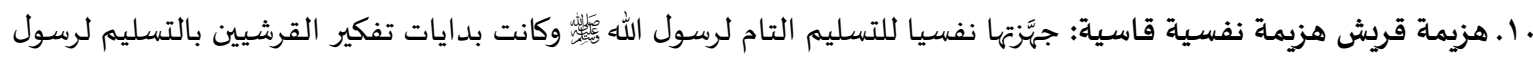

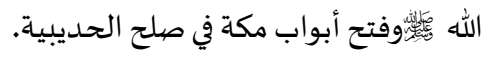




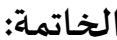

وفيها أهم النتائج والتوصيات

أولاً: النتائج:

بعد أن وفقني الله عز وجل إلى الوصهول إلى نهاية البحث وقد عالجت المسائل المتعلقة باه، فإنني أسجل أمورا وفقني الله لاستخلاصها. توصلت هذه الدراسة أن صلح الحديبية في خصائصها قد وافق المعاهدات الدولية من حيث أنه معاهدة هي اتفاق يعبر عن التقاء إرادات موقعيها على أمرٍ ما و المعاهدة هي اتفاق مكتوب وهو كذلك وان الصلح كان من ضمن الاتفاقيات الدهات الدولية الحديثة

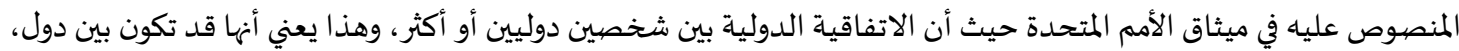
وقد تكون بين دولة ومنظمة دولية، وقد تكون بين منظمات دولية. والصلح نشاء لإنشاء حقوق وهذا مطابق للأعراف الدولية حيث

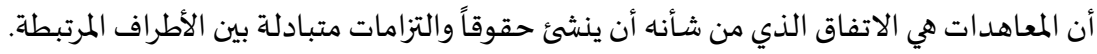

توصلت الدراسة انه يمكن تصنيف صلح الحديبية في المعاهدات الحديثة انه من ضمن معاهدات ثنائية وهذا من حيث أطراف المعادلة حيث كان بين المسلمين وقريش وهما طرفا المعادلة أما من حيث الطبيعة فهي معاهدة شارعة ومن حيث الشئ الشكل فكان الصلح من ضمن معاهدات مبسطة أو تنفيذية. توصلت الدراسة أن صلح الحديبية قد أشتمل على شروط المعاهدات الحديثة حيث كان الصلح من حيث أهلية التعاقد و الرضا و مشروعية موضيوع التعاقد. توصلت الدراسة أن صلح الحديبية قد مر بجميع مراحل إجراءات إبرام المعاهدة من حيث مرحلة التفاوض ومرحلة تحرير المعاهدة ومرحلة التوقيع ومرحلة التصديق والتحفظات والتسجيل والنشر. توصلت الدراسة أن صلح الحديبية يصنف في الفقه الإسلامي تحت مسمى الهدنة. ثانياً: التوصيات:

إبلاء موضيوع صلح الحديبية من الفقهاء المعاصرين والأساتذة الأفاضل من أصحاب العلم الشرعي مزيد من البحث حتى يعطوا

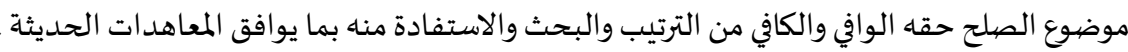
هالعمل على عقد المؤتمرات وعقد الندوات المتخصصة التي تناقش موضوع المعاهدات الدولية وايجاد نقاط مشتركة بيننا وبين الأمم الأخرى والاستفادة من تجاربهم بما يتوافق مع تعاليم الدين ويحقق لنا المصلحة. للخروج من الأزمة الحالية .

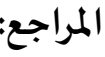

القران الكريم.

1. محاضرات في القانون الدولي العام ، القاهرة.

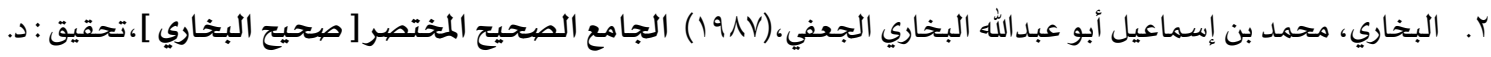
مصطفى ديب البغا أستاذ الحديث وعلومها في كلية الشريعة - جامعة دمشقى مع الكتاب : تعليق د. مصطفى ديب البغا، الناشر:

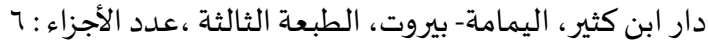

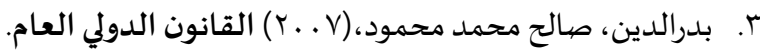

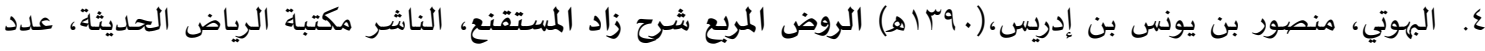
الأجزاءع

0. البهوتي، منصهور بن يونس بن إدريس، (r ع أه) كشاف القناع عن متن الإقناع، تحقيق هلال مصيلحي مصطفى هلال، الناشر ، دار الفكر، مكان النشر بيروت، عدد الأجزاء 7.

7. البيهقي، محمد ضياء الرحمن الأعظمي،( . . ب) شرح وتخريج السنن الصغرى للبيهقي السنن الصغرى - ت الأعظم الناشر :

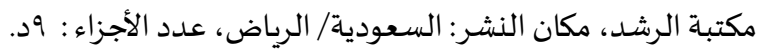
V. التميمي، عبد الله بن محمد بن عبد الوهاب بن سليمان التميهي،(199V) مختصبرسيرة الرسول صلى الله عليه وسلم، الناشر:

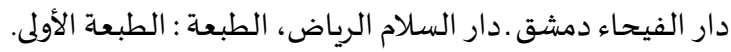

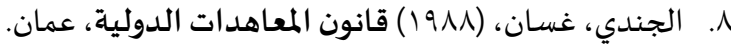

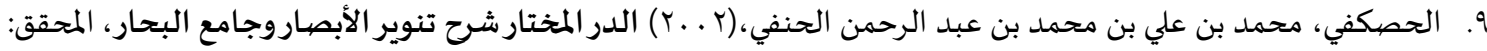




$$
\text { عبد المنعم خليل إبراهيم، الناشر: دار الكتب العلمية، رقم الطبعة: } 1 .
$$

• ا. الحصيني، تقي الدين أبي بكر بن محمد الحسيني الدمشقي الشافعي،(ع991) كفاية الأخيار في حل غاية الاختصار، تحقيق

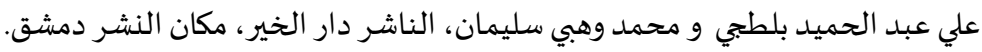

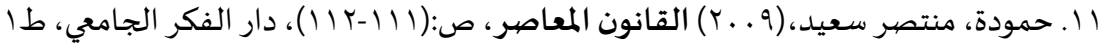

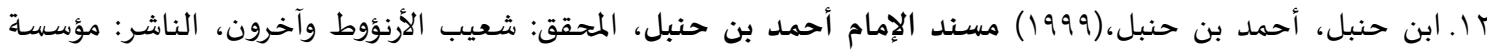
الرسالة، الطبعة : الثانياة.

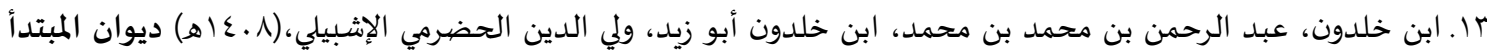

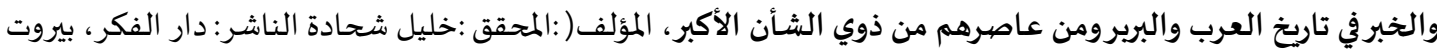
الطبعة :الثانية عا. الرازي، محمد بن أبي بكر بن عبدالقادر،(1990) مختار الصحاح، الناشر: مكتبة لبنان ناشرون- بيروت، تحقيق: محمود خاطر، الطبعة طبعة جديدة.

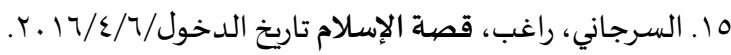

7 ا ـ السمرقندي،(ع991) تحفة الفقهاء دار الكتب العلمية، دار الكتب العلمية بيروت- لبنان، الطبعة الثانية. VIV السيوطي، أبو الفضل جلال الدين عبد الرحمن أبي بكر،(1910) الخصائص الكبرى، دار النشر: دار الكتب العلمية - بيروت. 1 1. السيوطي، عبد الرحمن بن أبي بكر السيوطي، (904) تاريخ الخلفاء [ تاريخ الخلفاء - السيوطي]، تحقيق : محمد مجي الدين

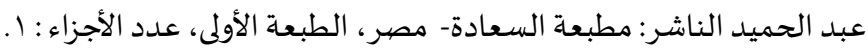

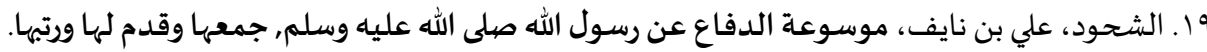

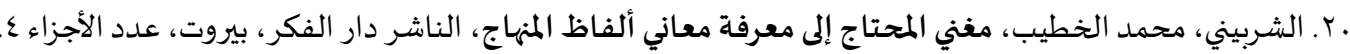

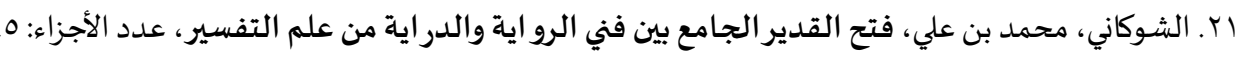

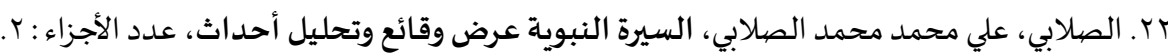

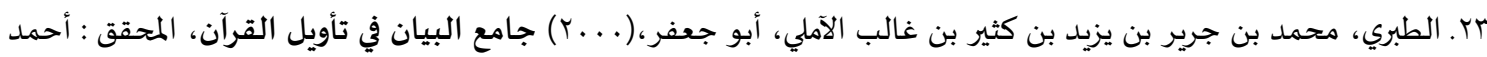

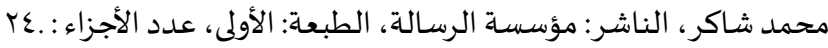

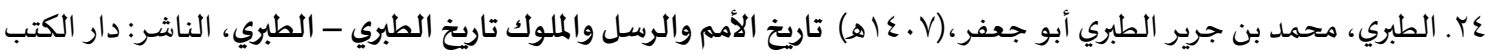

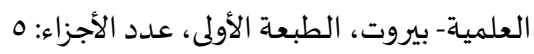

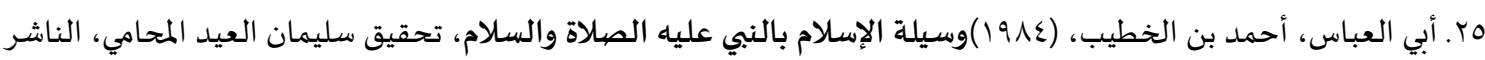

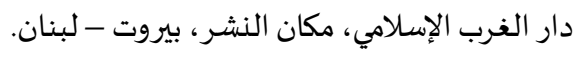

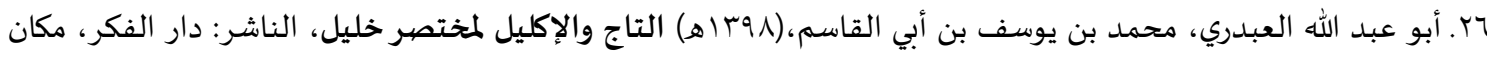

$$
\text { النشر بيروت. }
$$

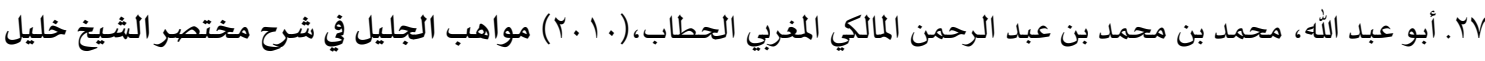

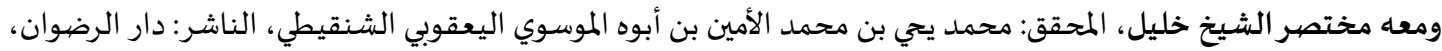

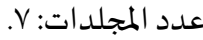

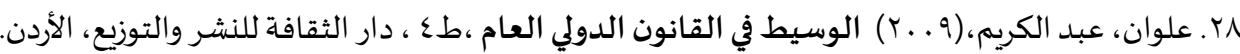

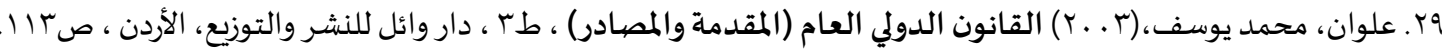

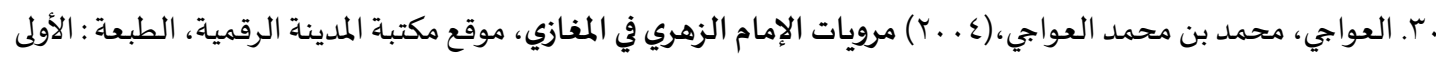

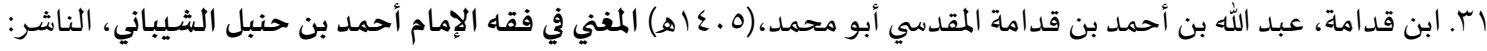
دار الفكر - بيروت، الطبعة الأولى.

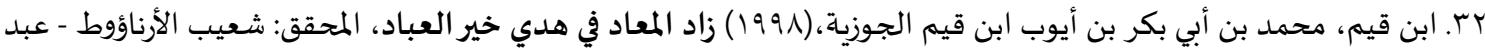

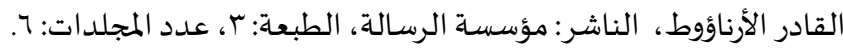

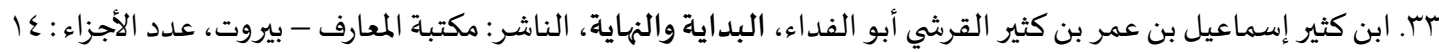

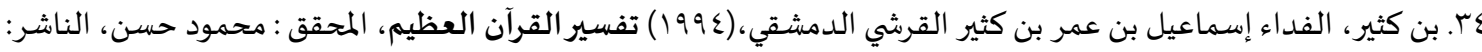
دار الفكر، الطبعة: الطبعة الجديدة. 
هr. محمد بن عمر بحرق الحضرمي الشافعي، (1991) حدائق الأنوارومطالع الأسرارفي سيرة النبي المختار، تحقيق محمد غسان

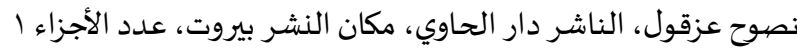

حس. ابن منظور، محمد بن مكرم بن منظور الأفريقي المصري، لسان العرب، الناشر : دار صيادر - بيروت الطبعة الأولى، عدد الأجزاء : .10

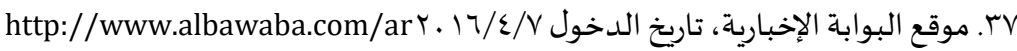

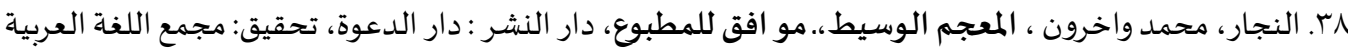

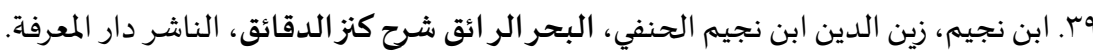

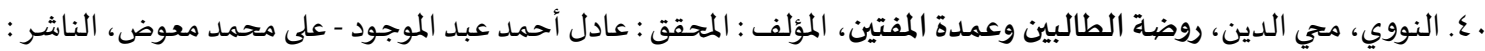
دار الكتب العلمياة، الجزء(. (1).

اع. هارون، عبد السلام، تهذيب سيرة ابن هشام، مصدر الكتاب : موقع الوراق، الموسوعة الشـاملة.

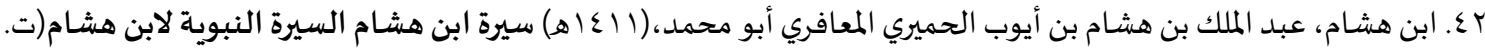

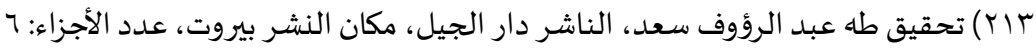




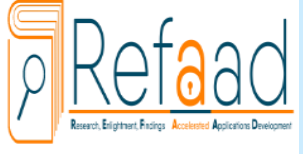

www.refaad.com
المجلة الدولية للدراسات الإسلامية المتخصصية

International Journal of Specialized Islamic Studies(SIS)

Journal Homepage: https://www.refaad.com/views/SIS/Home.aspx

ISSN: 2617-6246(Online) 2617-6238(Print)

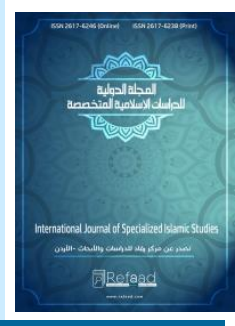

\title{
International treaties and Solh Al- Hudaybiyah (A comparative analytical study)
}

\author{
Dr. Wesam Mahmoud Al-Titi \\ Resercher, Jordan \\ wesam.titi@yahoo.com
}

DOI: https://doi.org/DOI:10.31559/sis2019.3.2.2

Abstract: The aim of this study is to study Solh Al- Hudaybiyah in terms of the stages it passed through and the extent of the reconciliation of peace with international treaties in the modern era. Also, how the reconciliation that was in the era of prophet Mohammad, peace be an blessing upon him, was compatible with the modern international treaties in the common era.

This study consists of three topics. In the first topic I talked about the linguistic and Idiomatic definition of the international treaties. As well as, the types, conditions and stages of modern treaties. The second topic is about the meaning of treaties according to Islamic jurisprudence. The evidence that was mentioned in the legitimacy of treaties from the Qur'an and Sunnah, and about the meaning of composition and the terms related to it.

The third topic consists of five requirements. The first demand is about Solh Al-Hudaybiyah, the second is about relationship of Solh Al-Hudaybiyah and Surat Al-Fateh, the third request is about the stages and terms of Al-Solh, the fourth requirement is a brief stop with Al-Solh and finally the fifth request is about the effect of it on Muslims. Finally I wrote the conclusion which includes the most important results and recommendations.

Keywords: Treaties; International; Solh; Al- Hudaybiyah.

\section{References:}

- Ạlqrạn Ạlkrym

[1] Ả̉by Ạl'bạs. Ảhmo Bn Ạlkhtỵb, Wsylë Ạlạslạm Bạlnby 'lyh Ạlṣlạh Wạlslạm, Tḥqyq Slymạn Ạl'yd

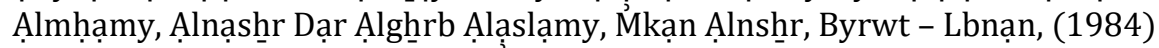

[2] Ạ̉bw 'bd Ạllh Ạl'bdry. Mḥmd Bn Ywsf Bn Ạ̉by Ạlqạsm, (1398h)Ạltạj WạlạKlyl Lmkḥtṣr Khlyl, Alnạsḩr : Dạr Alfkr, Mkạn Ạlnsḩr Byrwt Sn̈̈ Ạlwlạdh.

[3] Ảbw 'bd Allh, Mhmd Bn Mḥmd Bn 'bd Alrḥmn Almạlky Almghrby Alhṭạb, Mwạhb Aljlyl Fy Shrh

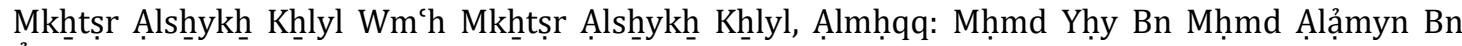
Ạ̉bwh Ạlmwswy Ạly`qwby Ạlshnnqyț, Ạlnạsḩr: Dạr Ạlrḍ̣wạn, 'dd Ạlmjldạt: 7, (2010)

[4] 'lwạn. 'bd Ạlkrym, Ạlwsyț Fy Ạlqạnwn Ạldwly Ạl'ạm ,Ṭ4 , Dạr Ạltḥqạfh Llnsh̆r Wạltwzyc, Ạlạ̉rdn, (2009)

[5] 'lwạn. Mḥmd Ywsf, Alqạnwn Ạldwly Ạl'ạm (Ạlmqdmh Wạlmṣạdr), Ț3 , Dạr Wậ̉l Llnsh̆r Wạltwzy', Ạlạ̉rdn, (2003), Ș113 .

[6] Ạlcwạjy. Mḥmd Bn Mḥmd Ạl'wạjy, Mrwyạt Ạlạ̣ạm Ạlzhry Fy Ạlmghạzy, Mwq' Mktbë Ạlmdynh Ạlrqmyh, Ạlțb`h : Ạlạ̉wla, (2004)

[7] Ạ̉ḥmd Ạ̉skndry \& Bw Gḥzạlh. Mḥmd Nạṣr , Mḥạdrạt Fy Ạlqạnwn Ạldwly Ạl'ạm , Ạlqạhrh, (1998)

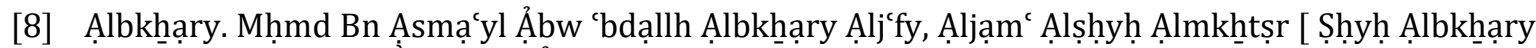

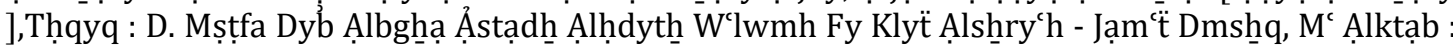

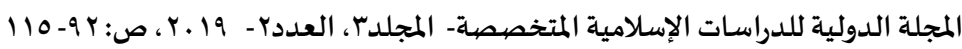




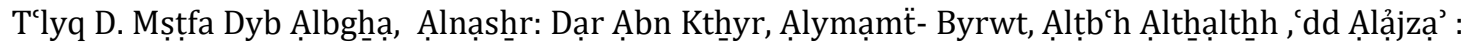
6, (1987)

[9] Bdrạldyn. Șạlḥ Mḥmd Mḥmwd, Ạlqạnwn Ạldwly Ạl'ạm, (2007)

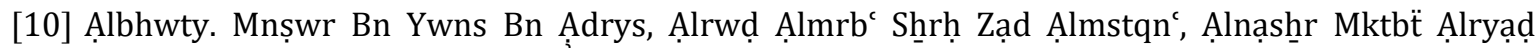
Ạlḥdythֵh, 'dd Ạlạjjzậ'4, (1390h)

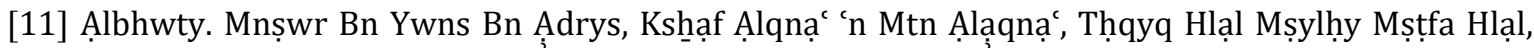

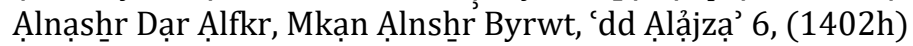

[12] Ạlbyhqy. Mḥmd Dyạ’ Ạlrḥmn Ạlặç̣my, Shrḥ Wtkhhryj Ạlsnn Ạlṣghry Llbyhqy Ạlsnn Ạlṣghnry- T

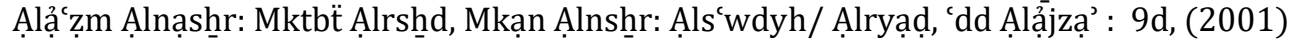

[13] Hạrwn. 'bd Ạlslạm, Thdhyb Syrh Ạbn Hshạam, Mṣdr Ạlktạb: Mwq Ạlwrạq, Ạlmwsw'h Ạlshạmlh.

[14] Ḥmwdh. Mntṣr S`yd, Ạlqạanwn Ạlm’ạṣr, Ṣ:(111-112), Dạr Ạlfkr Ạljạmy, Ṭ1, (2009)

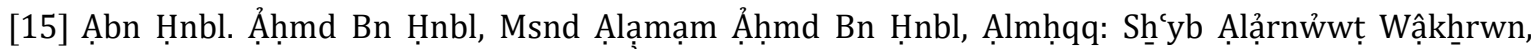

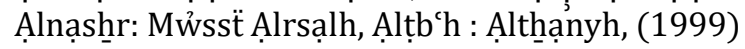

[16] Ạbn Hshạm. 'bd Ạlmlk Bn Hshạm Bn Ạ̉ywb Ạlhmmyry Ạlmạ̣fry Ạ̉bw Mḥmd, Syrh Ạbn Hshạm Ạlsyrh

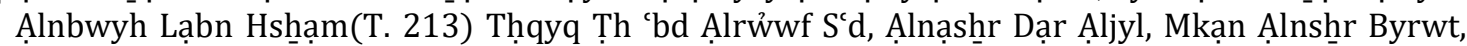
'dd Ạlạjzậ' 6, (1411h)

[17] Ạlḥskfy. Mḥmd Bn 'ly Bn Mḥmd Bn 'bd Alrḥmn Ạlḥnfy, Ạldr Almkḥtạr Sh̆rḥ Tnwyr Alạ̉bṣạr Wjạm Ạlbhạr, Ạlmḥqq: 'bd Ạlmn'm Khlyl ẠBrạhym, Ạlnạsḩr: Dạr Ạlktb Ạl'lmyh, Rqm Ạlțb'h: 1, (2002)

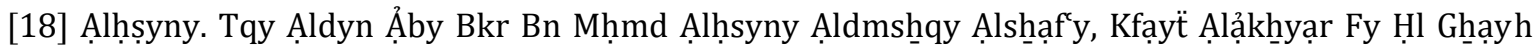

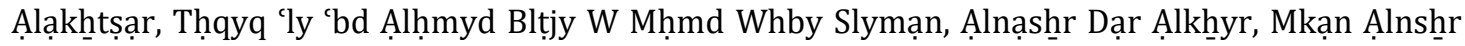
Dmshq, (1994)

[19] Ạljndy. Ghsạn, Qạnwn Ạlm’ạhdạt Ạldwlyh, 'mạn, (1988)

[20] Abn Khldwn. 'bd Alrḥmn Bn Mhmd Bn Mhmd, Abn Khldwn Ạ̉bw Zyd, Wly Aldyn Ạlhḍrmy Ạlạshbbyly, Dywạn Ạlmbtdạ̉ Wạlkhhbr Fy Tạrykh Ạl'rb Wạlbrbr Wmn 'ạșrhm Mn Dhwwy Ạlshạ̉n

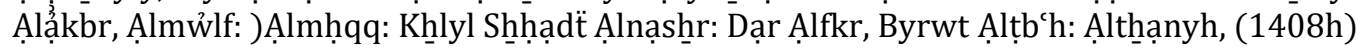

[21] Ạbn Kthyyr. Asmạcyl Bn 'mr Bn Kthyyr Ạlqrshy ạ̉bw Ạlfdạ', Ạlbdạyh Wạlnhạyh, Ạlnạshnr: Mktbë Ạlm'ậrf - Byrwot, 'dd Ạlạjzzạ' : 14

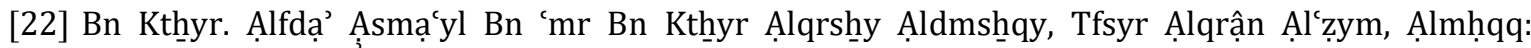
Mḥmwd Ḥsn, Ạlnạshhr: Dạr Ạlfkr, Ạlțbh: Ạlț̣bh Ạljdydh, (1994)

[23] Mhmd Bn 'mr Bḥrq Alhḍdrmy Ạlshạf'y, Ḥdạ̉q Alạ̉nwạr Wmțạl` Alạ̉srạr Fy Syrë Alnby Almkhtạr,

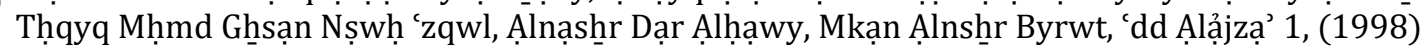

[24] Ạbn Mnzwr. Mḥmd Bn Mkrm Bn Mnẓwr Ạlậfryqy Ạlmșry, Lsạn Ạl'rb, Ạlnạsḩr: Dạr Ṣadr- Byrwt Ạlțb'h Ạlạ̉wlȳ, 'dd Ạlạ̉zzạ’ : 15.

[25] Mwq Ạlbwạbh Ạląkhbạryh, Tạrykh Ạldkhِwl 7/4/2016 http://www.albawaba.com/ar

[26] Ạlnjạr. Mḥmd Wạkḥrwn, Ạlmjm Ạlwsyț, Mwạfq Llmțbw'c, Dạr Ạlnsȟr : Dạr Ạld'wë, Tḥqyq: Mjmc Ạllghh Ạl'rbyh

[27] Ạbn Njym. Zyn Ạldyn Ạbn Njym Ạlḥnfy, Ạlbḥr Ạlrậđq Shrhḥ Knz Ạldqậ̉q, Ạlnạsȟr Dạr Ạlmrrfh.

[28] Ạlnwwy. Mḥy Ạldyn, Rwḍ̂̈ Ạlțạlbyn W'mdë Ạlmftyn, Ạlmw̉lf : Ạlmḥqq: ‘ạdl ạ̉ḥmd 'bd Ạlmwjwd 'ly Mḥmd M'wḍ, Ạlnạsḩr: Dạr Ạlktb Ạl'lmyh, Ạljz'(10).

[29] Ạbn Qdạmh. 'bd Ạllh Bn Ạ̉ḥmd Bn Qdạm. Ạlmqdsy Ạ̉bw Mḥmd, Ạlmghhny Fy Fqh ẠlạMạm Ạ̉ḥmd Bn Ḥnbl Ạlshybạny, Ạlnạshnr: Dạr Ạlfkr- Byrwt, Ạlțbch Ạlạ̉wly, (1405h)

[30] Abn Qym. Mhmd Bn Ả̉by Bkr Bn Ảywb Ạn Qym Aljwzyh, Zạd Ạlmaạd Fy Hdy Khyr Al'bạd, Ạlmḥqq: Shcyb Ạlạ̉rnạwwțt - 'bd Ạlqạdr Ạlạ̉rnậwwțt, Ạlnạshnr: Mw̉ssẗ Ạlrsạlh, Altṭb'h: 3, 'dd Ạlmjldạt: 6, (1998)

[31] Alrạzy. Mḥmd Bn Ạ̉by Bkr Bn 'bdạlqạdr, Mkhtạr Ạlṣhạh, Ạlnạshrr: Mktbë Lbnạn Nạshrwn- Byrwt, Tḥqyq: Mḥmwd Khạtr, Alț̣b`h Ṭbđ̈ Jdydh, (1995) 


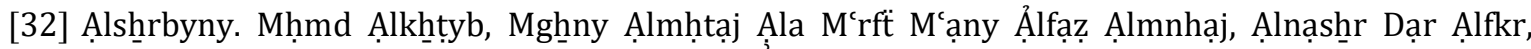
Byrwt, 'dd Alạ̉jzạ’ 4.

[33] Ạlsȟwkạny. Mḥmd Bn 'ly, Ftḥ Ạlqdyr Ạljạm Byn Fny Ạlrwạyh Wạldrạyh Mn 'Im Ạltfsyr, 'dd Ạlạ̉zzạ’: 5 .

[34] Ạlṣlạby. 'ly Mḥmd Mḥmd Ạlṣlạby, Ạlsyrh Ạlnbwyh 'rḍ Wqạỷc Wtḥlyl ạ̉ḥ̣dạthِ, 'dd Ạlạ̉jzậ' : 2.

[35] Ạlsrjạny. Rạghnb, Qṣ̂̈ Ạląsslạm Tạrykh Ạldkhwwl/6/4/2016.

[36] Ạlsmrqndy, Tḥft Ạlfqhạ’ Dạr Ạlktb Ạl'lmyh, Dạr Ạlktb Ạl'Imyh Byrwt- Lbnạn, Ạlṭb`h Ạlthạnyh, (1994)

[37] Ạlsywțy. Ạ̉bw Ạlfạl Jlạl Ạldyn 'bd Ạlrḥmn Ạ̉by Bkr, Ạlkḥṣạyṣ̣ Ạlkbry, Dạr Ạlnshַr: Dạr Ạlktb Ạl'lmyh - Byrwt, (1985)

[38] Ạlsywțy. 'bd Ạlrḥmn Bn Ạ̉by Bkr Ạlsywțy, Tạrykh Ạlkhlfạ’ [ Tạrykh Ạlkḥlfạ’ - Ạlsywty], Tḥqyq :

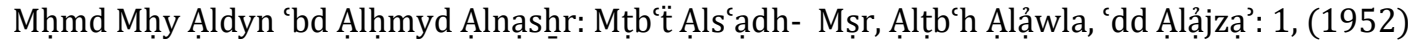

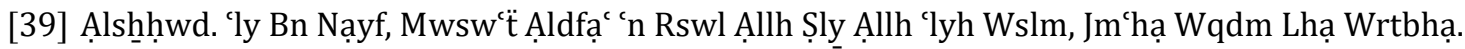

[40] Alttbry. Mhmd Bn Jryr Bn Yzyd Bn Kthyr Bn Ghạlb Alậmly, Ạ̉bw J'fr, Jạm Albyạn Fy Tạ̉wyl Alqrận, Ạlmḥqq : Ạ̉hmo Mḥmd Shạkr, Ạlnạshnr: Mw̉ssë Ạilrsạlh, Ạlṭb'h: Ạlạ̉wla, 'dd Ạlạ̉jzạ’ : .24, (2000)

[41] Allțbry. Mḥmd Bn Jryr Altṭbry Ạ̉bw J'fr, Tạrykh Alạ̉mm Wạlrsl Wạlmlwk Tạrykh Ạlțbry- Allṭbry, Ạlnạshrr: Dạr Ạlktb Ạl'lmyh- Byrwt, Ạlțb'h Ạlạ̉wla, 'dd Ạlạ̉jzạ’' 5, (1407h)

[42] Altmymy. 'bd Ạllh Bn Mhmd Bn 'bd Ạlwhạb Bn Slymạn Altmymy, Mkhtș̣r Syrë Ạlrswl Ṣly Ạllh clyh

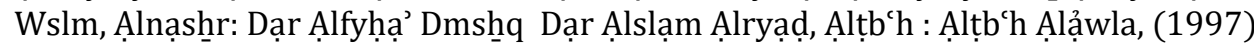

